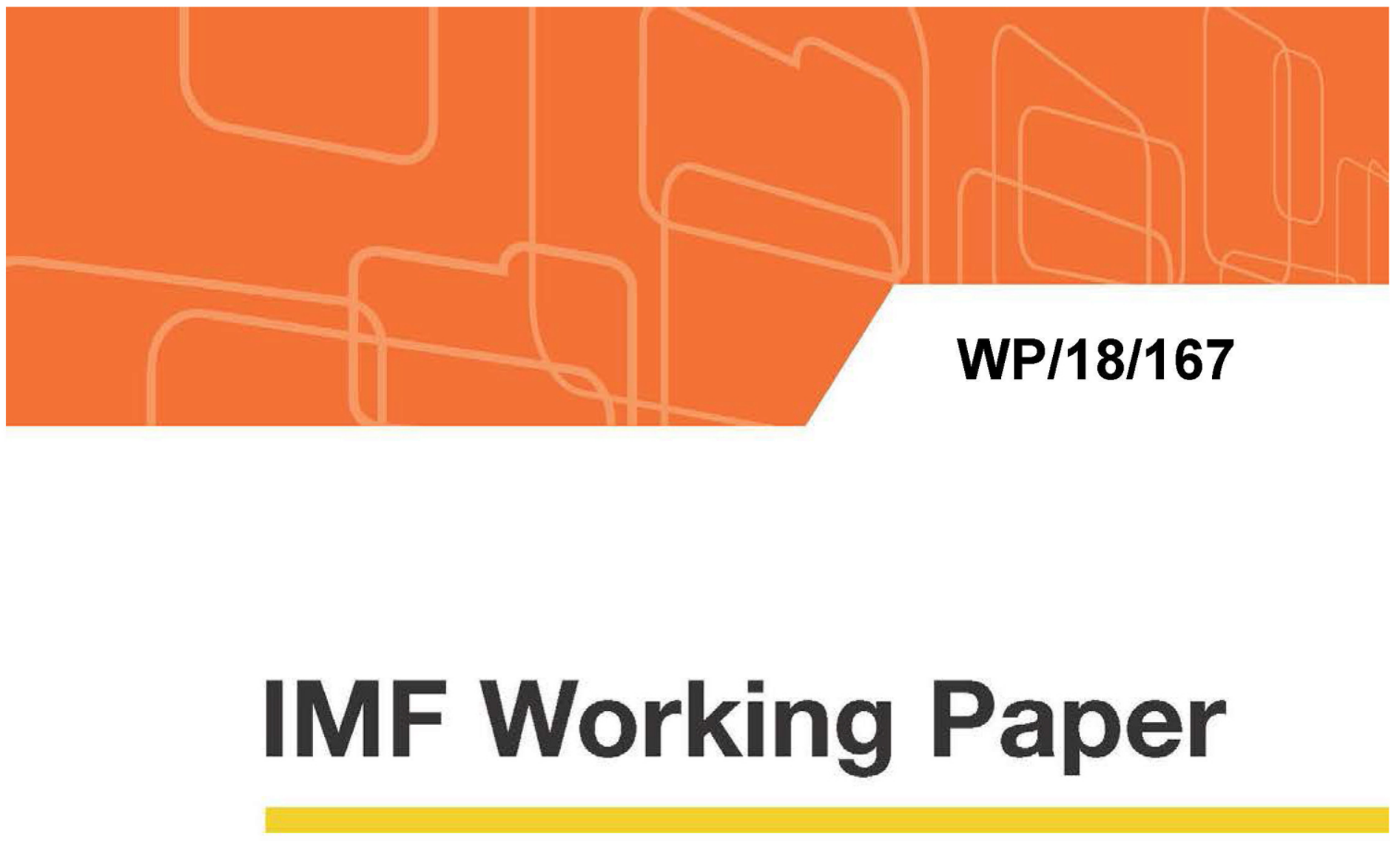

\title{
Inflation News and Euro Area Inflation Expectations
}

by Juan Angel Garcia and Sebastian Werner

IMF Working Papers describe research in progress by the author(s) and are published to elicit comments and to encourage debate. The views expressed in IMF Working Papers are those of the author(s) and do not necessarily represent the views of the IMF, its Executive Board, or IMF management. 


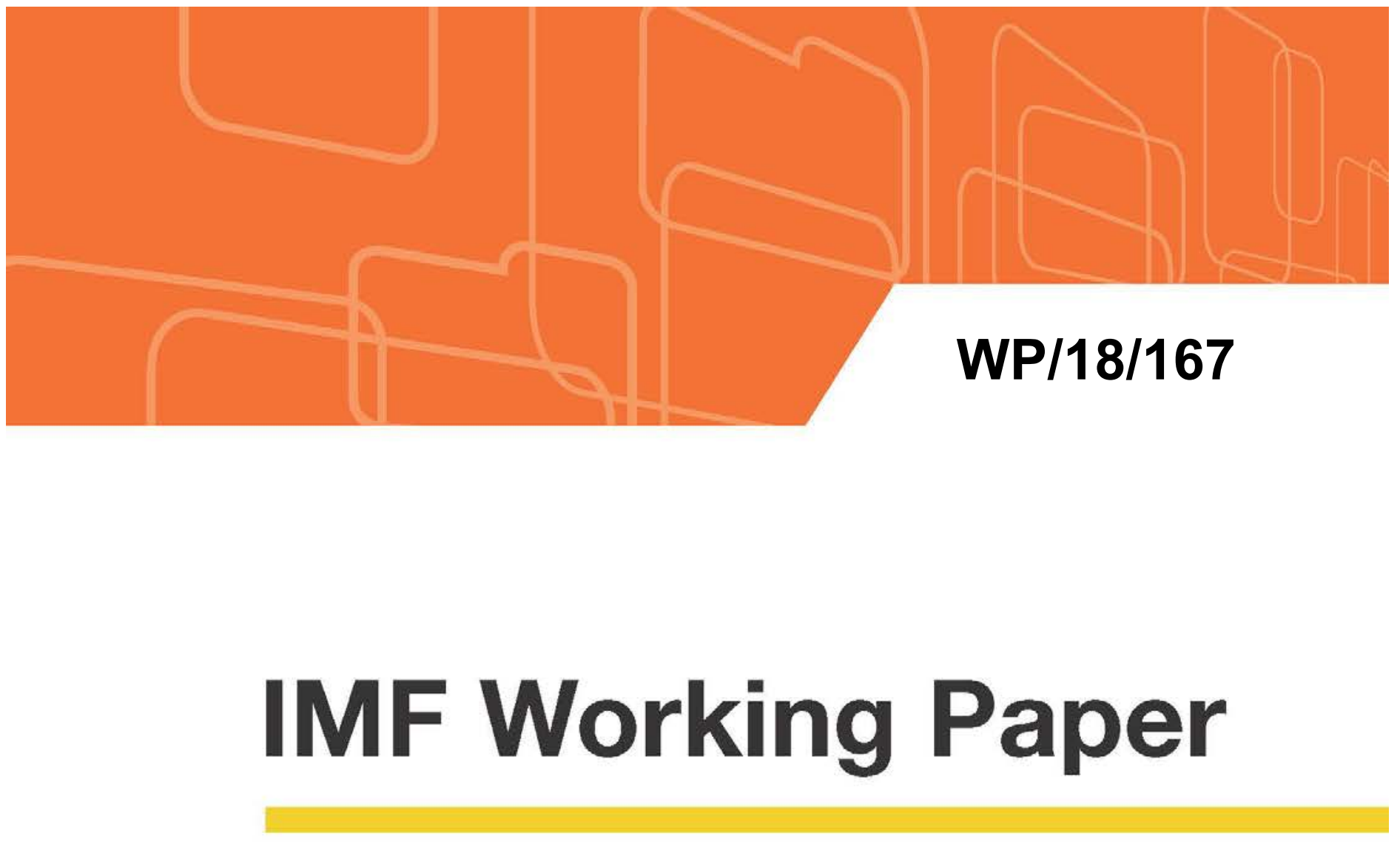

\section{Inflation News and Euro Area Inflation Expectations}

by Juan Angel Garcia and Sebastian Werner

IMF Working Papers describe research in progress by the author(s) and are published to elicit comments and to encourage debate. The views expressed in IMF Working Papers are those of the author(s) and do not necessarily represent the views of the IMF, its Executive Board, or IMF management.

I N T E R N A T I O N A L M O N E T A R Y F U N D 


\title{
IMF Working Paper
}

\author{
Asian Pacific Department
}

Inflation News and Euro Area Inflation Expectations

Prepared by Juan Angel Garcia and Sebastian Werner

Authorized for distribution by Lamin Leigh

July 2018

\begin{abstract}
IMF Working Papers describe research in progress by the author(s) and are published to elicit comments and to encourage debate. The views expressed in IMF Working Papers are those of the author(s) and do not necessarily represent the views of the IMF, its Executive Board, or IMF management.
\end{abstract}

\begin{abstract}
Do euro area inflation expectations remain well-anchored? This paper finds that the protracted period of low (and below-target) inflation in the euro area since 2013 has weakened their anchoring. Testing their sensitivity to inflation and macroeconomic news, this paper expands existing results in two key dimensions. First, by analyzing all available (advanced) inflation releases. Second, the reactions of expectations are investigated at daily, time-varying and intraday frequency regressions to add robustness to our conclusions. Results point to a significant impact of inflation news over recent years that had not been observed before in the euro area.

JEL Classification Numbers: E31, E52, E58

Keywords: inflation, market-based inflation expectations, macroeconomic news, monetary policy

Author's E-Mail Address: jgarcia@,imf.org, sebastian.e.werner@gmail.com

Acknowledgements: We thank Matteo Ciccarelli, Christian Speck and other participants in the Eurosystem Low Inflation Task Force for useful discussions, as well as Federico Grinberg, Li Lin, and Anne-Charlotte Paret for comments on a previous draft. Excellent research assistance by Renate Dreiskena and Patrick Markowicz is gratefully acknowledged. Remaining errors are our responsibility
\end{abstract}




\section{Contents}

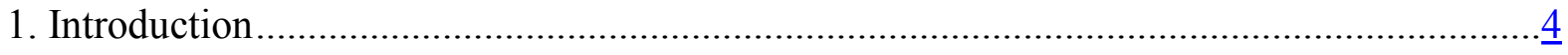

2. News and inflation expectations in the euro area …................................................. $\frac{8}{8}$

2.1 Macroeconomic releases and economic news ....................................................... $\frac{8}{8}$

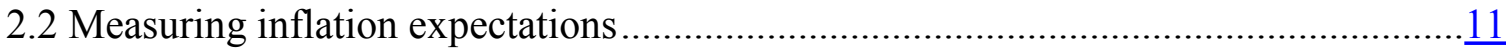

3. Assessing the anchoring of inflation expectations .........................................................

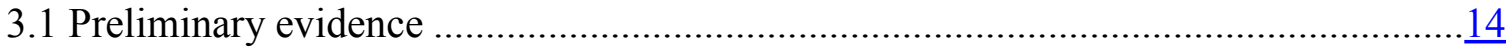

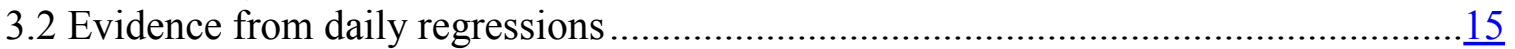

3.3 Evidence from time-varying regressions .................................................... $\frac{16}{20}$

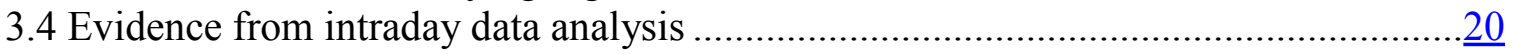

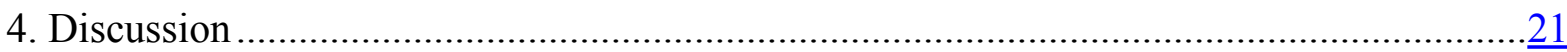

4.1 The importance of the timing of macroeconomic and inflation news .......................22

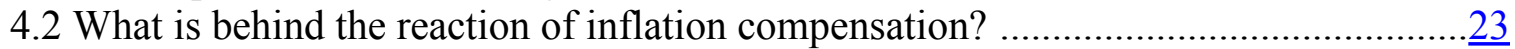

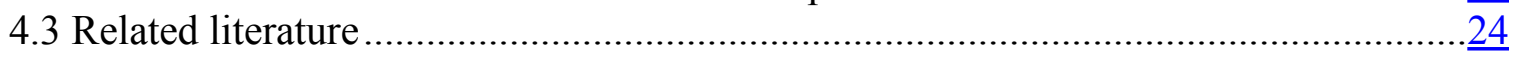

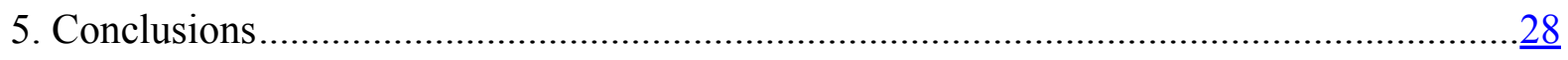

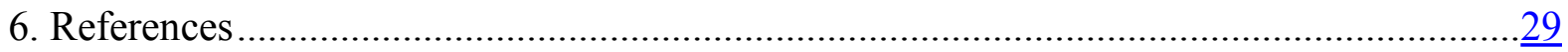

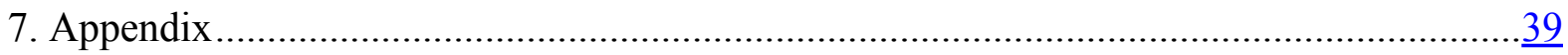

Figures

Figure 1: Actual inflation, market-based and survey long-term inflation expectations ......... $\underline{32}$

Figure 2: Schedule of Flash and HICP inflation data releases...................................... $\underline{33}$

Figure 3: Time varying sensitivity: coefficients $\delta^{t}$ from non-linear regression.................... 37

\section{Tables}

Table 1: Daily changes in EA long-term inflation compensation around data releases ......... $\underline{34}$

Table 2: Daily regression: Coefficient estimates $\beta$ from linear regression ......................... $\underline{35}$

Table 3: Daily regression: Coefficient estimates $\beta$ from linear regression (individual releases)

Table 4: Intraday regression: Coefficient estimates of $\beta$ from linear regression (individual

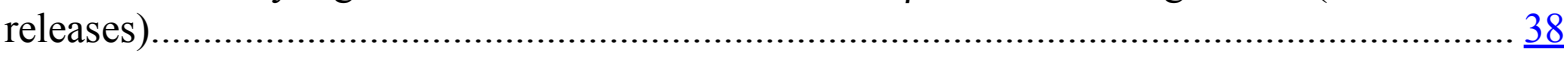




\section{Introduction}

The monetary transmission mechanism is most effective when long-term inflation expectations are strongly anchored. The analysis of inflation expectations has therefore become a crucial element of modern monetary policy, and an important research topic. Indeed, most central bank's public statements, speeches (e.g. Bernanke 2007, Draghi, 2014, 2018; Yellen, 2015) and specialized press and market commentary (e.g. The Economist, 2014, 2017; Financial Times, 2016) nowadays provide a detailed account on the evolution of inflation expectations.

In the case of the euro area, interest on long-term inflation expectations has taken even more prominence in recent years. Since early 2013 inflation has remained well below the $2 \%$ level consistent with the European Central Bank's (ECB) quantitative definition of price stability. Such a protracted period of below-target inflation is unprecedented since the launching of the single monetary policy in 1999. While there is consensus that the ECB managed to attain a significant degree of credibility ahead of the Global Financial Crisis (GFC henceforth), and even during the subsequent European debt crisis, the situation over more recent years is less clear. Indeed, even more than three years after the expansion of the ECB's unconventional policy measures to sovereign bond purchases, there has not been any convincing upward trend in inflation yet (Draghi, 2018).

Against this background, the goal of this paper is to investigate whether the anchoring of euro area inflation expectations has weakened in recent years. We assess changes in the anchoring of inflation expectations by the reaction of long-term inflation expectations to macroeconomic data releases. The rationale for this analysis is that, if expectations are well anchored, far ahead inflation expectations should not be significantly affected by news about the current state of the economy, which should only be informative to update the short-term outlook.

As measure of long-term inflation expectations we use forward inflation-linked (IL) swap rates, in line with existing literature for the euro area and other major economies (e.g. Gürkaynak, Levin and Swanson, 2010, Galati, Poelhekke and Zhou, 2011). The euro area IL swap market is arguably the most liquid in the world, and IL swap rates offer some important advantages over other indicators of inflation expectations. IL swaps are actively traded at 
higher frequency than survey data. ${ }^{1}$ In addition, since they only involve an exchange of flows (no principal payment), IL swap rates - in contrast to bond-based break-even inflation ratesshould not incorporate, or at most a very small, liquidity risk premium. As any financial asset, IL swap rates however comprise both the level of inflation expectations and the inflation risk premium associated to the risks surrounding them. Since inflation (and macroeconomic news in general) may trigger changes in the perceived risk surrounding future inflation, the inflation risk premium required by investors is also an important dimension of the anchoring of inflation expectations for monetary policy. More specifically, this paper focuses on whether the reaction of the five-year IL forward swap rate in five years - the most prominent measure of market-based euro area inflation expectations (Draghi, 2014) - to inflation and other macroeconomic news has changed since 2013. Evidence of a statistically significant change would suggest that the protracted below-target period has influenced market participants' perceptions of euro area inflation over the long-term.

To assess whether the anchoring of euro area inflation expectations has weakened since 2013, we implement three different but complementary pieces of analysis. First, we use daily regressions over different subsamples, expanding the approach in most previous literature on the anchoring of euro area inflation expectations in two key aspects. By using data upto March 2017, we have a sufficient sample over which testing whether the below-target period since 2013 has triggered a change in the reaction of long-term inflation compensation. In addition, we provide a detailed description of the information flow of news about inflation in the specific case of the euro area. The euro area market for IL products has the unique feature of comprising several different economies. As a result, country-specific data add a crucial additional dimension to the information flow, particularly about inflation, that needs to be taken into account when assessing market reactions to news. Specifically, advance releases of inflation - the so-called flash estimates for German, Spanish and Italian inflation ${ }^{2}$ - have been released since 2005 ahead of the euro area-wide flash estimate, the advance estimate

\footnotetext{
${ }^{1}$ Survey measures are available at quarterly (ECB's survey of professional forecasters) and semi-annual frequency (Consensus Economics), while market-based inflation expectations are available at daily or even intraday frequency. In addition to low frequency, survey measures have several additional shortcomings, as panelists have litttle incentive to continously update or even reveal their true forecasts, survey responses may not be internally coherent (e.g. García and Manzanares, 2007), there is subtantial dissagreement among panelists and may have become very disconnected from actual inflation over the most recent years (Chan, Clark and Koop, 2018; Coibion and Gorodnichenko, 2015).

${ }^{2}$ A flash estimate for HICP inflation in France has also been released since early 2016. As a crucial dimension of our analysis is the comparison to earlier periods, we however exclude it from our analysis.
} 
of euro area-wide inflation, and Harmonized Index of Consumer Prices (HICP henceforth) inflation releases. Failing to account for those country flash estimates ignores the most relevant pieces of news on inflation, and may therefore cast doubts on the conclusions about the anchoring of inflation expectations.

Second, we complement our subsample analysis with time-varying estimation of the response of inflation compensation to inflation news. As most inflation (and macroeconomic) releases only occur once a month, to overcome the short sample problem inherent in standard rolling regressions, we adapt the empirical approach recently introduced by Swanson and Williams (2014) to the flow of news on euro area inflation, and gauge evidence of changes in sensitivity to news using time-varying regressions.

Finally, we also provide novel additional evidence on intraday reactions of inflation compensation. Daily-frequency regressions are always subject to influences from additional news. Even a careful selection of release dates and additional control variables may not completely isolate that reaction in the data-rich environment in which financial markets nowadays operate. Intraday data on euro area inflation compensation measures are unfortunately only available since late 2008, but we can cross-check the reaction to news since 2013 and compare it to the previous years using intraday trading evidence.

Our results point to a deterioration in the anchoring of euro area long-term inflation expectations since 2013. Daily-frequency regressions corroborate existing findings of no sensitivity of long-term inflation compensation to non-inflation news releases over the whole sample. In contrast, the reaction to inflation news, which had also been non-significant before 2013, becomes statistically significant in the latter part of our sample. Importantly, statistically significant reactions mainly refer to the release of flash estimates at country level, specifically the German and the Spanish HICP flash estimates, which are respectively the two first pieces of news about each month's inflation in the euro area. These findings are robust to controlling for additional market and macroeconomic information.

Time-varying regressions also point to a significantly higher reaction of long-term inflation compensation to inflation news since the euro area inflation rate has remained below target. Moreover, while previous periods of high sensitivity, for example over the spring of 2008 when surging oil prices pushed actual inflation to their highest levels in euro area history, were short-lived, the responsiveness of long-term inflation compensation to inflation news 
has remained stubbornly high since mid-2013. In addition, two years after its launching, the ECB's sovereign bond purchases programme seems to have not been able to attenuate that high sensitivity so far.

Novel analysis using intraday data provides further support for a weakening in the anchoring of euro area long-term inflation expectations in the later part of our sample. Between 2013-2017, we find statistically significant reactions to the release of the flash estimates for Germany and Spain, as well as of the Spanish HICP over a 120 minute window from the data release. Over a shorter time window of 15 minutes, the reaction is somewhat more muted, but nonetheless statistically significant for the German flash and also the euro area flash estimate.

This paper belongs to a stream of literature that has emerged over the last decade with the development of IL markets. Quantitative evidence on the sensitivity of inflation compensation to macroeconomic news has been used to address several different policy questions, from the role of an explicit inflation target using international evidence (e.g. Gürkaynak et al, 2010; Beechey, Johannsen and Levin, 2011), to the impact of the financial crisis and the euro area debt crisis (e.g. Galati at el, 2011, Autrup and Grothe, 2014, Speck, 2016). Our focus is the impact of the protracted period of below-target inflation since 2013 on long-term inflation expectations (see Figure 1).

[Figure 1 around here]

From a research perspective, this paper contributes to that stream of literature in three specific aspects: employing a larger set of news than most existing papers (particularly the early releases of inflation at country level), combining three different pieces of analysis (daily frequency, time-varying and for the first time intraday regressions) and using a larger sample 2005:01-2017:03. These three contributions help us document robust evidence on the evolution of the anchoring of long-term inflation expectations in the euro area and its deterioration since 2013, corroborating and in some aspects qualifying some of the existing results over shorter samples.

The remainder of the paper is organized as follows. Section 2 discusses the data we employ in our analysis. Specifically, we explain in detail the flow of macroeconomic news in the euro area, in particular regarding inflation. We also provide an overview of recent developments in long-term inflation expectations, both from surveys and the euro area IL swap market, and 
the characteristics of inflation compensation in the euro area. Section 3 reports our empirical results. The main findings from daily frequency, time-varying and intraday data regressions are described in detail. Section 4 contains and additional discussion of some of our findings and places them in the context of the related literature and existing results. Finally, Section 5 concludes.

\section{News and inflation expectations in the euro area}

The main goal of this paper is to assess changes in the anchoring of inflation expectations in the euro area over time. To that end, our metric is the reaction of long-term inflation expectations to macroeconomic news in general, and about inflation in particular, by means of event-study techniques. The significant development of financial markets for inflationlinked products and the lumpy manner in which inflation and other macroeconomic releases provides a great opportunity for researchers to carry out event studies, as identification challenges in the search for robust evidence of causality are significantly eased using highfrequency financial market data (Gürkaynak and Wright, 2013).

Carrying a meaningful event-study analysis on euro area data requires to take into account some specificities of euro area macroeconomic data releases and financial market indicators. Before embarking in our empirical analysis, we discuss some important characteristics of the flow of macroeconomic news and the market for inflation-linked products.

\subsection{Macroeconomic releases and news}

The flow of news is a fundamental aspect to bear in mind when analyzing macroeconomic news in the euro area. Financial markets nowadays operate in a data-rich environment (Bernanke and Boivin, 2003), and indeed evidence suggest that market participants do monitor a large number of macroeconomic indicators (e.g. Bartsch et al, 2014, Swanson and Williams, 2014). Given its unique characteristics as a monetary union comprising a relatively large number of countries, the presence of a data-rich environment is even more extreme in the case of euro area financial markets.

In addition to the amount of relevant news, the timing of the macroeconomic releases in another important piece of information to take into account. In the euro area, particularly regarding inflation news but also some other key macroeconomic series like the GDP, there 
are a number of key country-specific macroeconomic releases that precede the release of euro area aggregates. Failing to account for those country-specific releases can impair a proper understanding the reaction of inflation expectations to macroeconomic news and bias the empirical results.

Since we will focus on the reaction of long-term inflation expectations, we will pay particular attention to the news surrounding the releases of the HICP. There are two kinds of HICP releases in the euro area. Flash estimates are advanced estimates regularly issued by statistical offices. Eurostat releases a flash estimate for the euro area-wide HICP, but flash estimates are also issued for Germany, Spain and Italy (and since 2016 also France) by the corresponding national statistical institutes. Those country Flash estimates are normally limited to a figure for the year-on-year inflation rate for the current month, and do not contain a breakdown of the different sub-components (e.g. service or non-energy industrial goods inflation rates); the euro area flash only included a breakdown of main HICP sub-components since late 2012. The relevance of the flash estimates instead stems from the fact that they are released well ahead (about two or three weeks before) the full release for the corresponding country or the euro area-wide HICP.

Figure 2 illustrates the flow of inflation releases in the euro area. The x-axis indicates the number of business days between the release dates of the monthly flash estimates and the corresponding HICP with respect to the last business day of the reference month $m$. A zero on the $\mathrm{x}$-axis therefore indicates that a flash estimate is released on the last day of the month to which it refers, negative numbers indicate the number of days before the end of the month (the most common situation), while positive numbers point to days into the month following the one to which the flash release refers. More formally, flash $h_{m, t}$ provides an estimate of $H I C P_{m, t}$ for the corresponding country or the euro area in month $m$.

[Figure 2 around here]

Dates of the inflation releases nonetheless vary from month to month across countries, depending on data collection and processing. A triangle in Figure 2 indicates the average business day of the inflation data release and the whiskers represent the distribution in the release dates. For example, the German flash estimate is released on average 2 business days within the reference month, the earliest among the flashes (the Spanish flash is released 1 day ahead the end of the month while the Italian and the euro area-wide flash tend to be 
released 1 day into the following month). All flash estimates are nonetheless released ahead of the corresponding HICP inflation releases, and take place into the month following the reference period: 9 days for the German, 10 for the Spanish and the French, 11 for the Italian and about 13 days for the euro area after the end of the reference month.

Besides inflation data releases, we also consider data releases for other major euro area macroeconomic series to provide an ample coverage of factors shaping the macroeconomic situation in the euro area, and therefore potentially having an impact on inflation expectations. Specifically, we consider producer price index (PPI), Gross Domestic Product (GDP), purchasing manager's index (PMI), consumer confidence, industrial confidence and production (new orders, unemployment rate, growth of the monetary aggregate (M3), retail sales and trade balance. ${ }^{3}$ A complete list of the series can be found in Table 1.

Financial markets are forward-looking and, under the efficient markert hypothesis all available and expected information should be priced in, so only the "unexpected" or "news" component of macroeconomic data releases should lead to changes in inflation compensation. We measure the news component of each release using the macroeconomic expectations collected by Bloomberg L.P. from a selection of professional economists until soon before the release takes place. For most of the key country and area-wide macroeconomic releases, Bloomberg provides the actual data release, together with a large number of characteristics of the expectations collected among market participants (mean, median, highest and lowest values, number of participants...). ${ }^{4}$ In our econometric analysis, we use euro area-wide and some key country releases for which Bloomberg has collected expectations over a large part of our sample.

We compute the surprise component for each data release as the difference between the actual values of the official release and the Bloomberg survey expectations for each variable $k$ for reference period $t$. Using the surprise component of the releases also removes any issues of endogeneity arising from prevailing inflation expectations feeding back to the macroeconomy, because any such effects, to the extent that they are predictable, should be already incorporated into market expectations for the release.

\footnotetext{
${ }^{3}$ We also collect market expectations about ECB's policy rates, but as the ECB was highly predictable there were very few monetary policy surprises over our sample. The expectation collection was also extendedbeyond policy rates following the introduction of some UMP measures (e.g. negative rates), but they are available over a too short a period for our analysis.

${ }^{4}$ The information also includes the specific time of the announcement, which we will further exploit in our intraday analysis, see Section 3.4.
} 


\subsection{Measuring inflation expectations}

Over the last two decades, the analysis of inflation expectations has been further reinvigorated by the issuance of bonds and derivatives (mainly swaps but also other financial instruments) whose payments are indexed to inflation developments in many advanced and emerging economies. The yield spread between comparable conventional and inflation-linked (IL) bonds is often referred to as the "break-even inflation rate" (BEIR) because it provides an estimate of the level of expected inflation at which a (risk-neutral) investor would be indifferent between holding either type of bond. BEIRs often provide more timely and comprehensive information (across time horizons) on investors' inflation expectations compared to survey-based expectations, and have become closely-monitored indicators.

In addition to the expected inflation, however, BEIRs and IL swap rates incorporate other factors, notably inflation risk premia, and should better be interpreted as the overall inflation compensation requested by investors to hold nominal assets. Inflation compensation measures should then be interpreted as an indicator of market participants' inflation expectations in a broader sense rather than a single point estimate, also comprising information on the market pricing of risks surrounding future inflation. Changes in inflation compensation measures could therefore reflect either changes in the level of expected inflation, changes in the perceived risks about future inflation or a combination of both. From a central bank's perspective, both components are of relevance. A credible commitment to price stability should anchor the level of expected inflation to its policy objective, with the degree of perceived uncertainty about future inflation developments providing relevant information about how firmly inflation expectations may be anchored.

We measure inflation compensation using data from the inflation-linked (IL) swap market in the euro area. Using bond-based BEIRs requires the estimation of nominal and real term structures from conventional and IL government bonds issued by euro area governments. The issuance of IL bonds in the euro area has remained relatively limited so far, ${ }^{5}$ at least compared to the Treasury Inflation-Protected Securities issuance in the United States for example. As a result, there is significant market segmentation in the euro area IL bond market, and the onset of the GFC and the subsequent euro area debt crisis has led to the presence of significant differences in sovereign and liquidity risk embodied in the prices of

\footnotetext{
${ }^{5}$ France, Italy, Germany, Spain and Greece have issued IL bonds in the euro area.
} 
those bonds.

Since a key goal of this paper is to assess the anchoring of inflation expectations, particularly since 2013, we instead use data from the euro area IL swap market. IL swaps - a derivative though which one party commits to pay a fixed rate of inflation in exchange for the actual inflation over the length of the contract - provide inflation compensation measures that, being solely based on net exchanges of flows at the end of the contract, should not incorporate a liquidity premium, and can therefore provide a cleaner measure of inflation compensation than bond-based BEIRs. ${ }^{6}$

The euro-area IL swaps market is arguably the most mature in the world, a very liquid market for actively hedging exposures to euro area-wide HICP (excluding tobacco). ${ }^{7}$ Market participants typically include pension funds willing to hedge their inflation exposures, but also a substantial arbitrage activity between the sovereign market for inflation-linked debt and the IL swap market. Given the limitations of the euro area sovereign IL bond market, the IL swaps have become a natural instrument to hedge inflation outcomes.

The most traded IL swaps are typically zero-coupon contracts, through which, net payments of a fixed rate of inflation are exchanged for a floating rate reflecting realized euro area inflation at maturity. In a zero-coupon IL swap, the fixed inflation rate leg of the swap reflects the compensation requested by the holder of the contract for expected inflation over the life of the contract plus a premium for bearing the uncertainty associated to future inflation, the inflation risk premium. Such an inflation compensation measure can be obtained directly from the market quotes, without the need to estimate the nominal and real zero-coupon term structures from traded bonds and therefore minimizing the impact of potential model mispecification in our analysis. Euro area IL swap contracts have been very actively traded since 2004 over a wide range of maturities from 1 to 30 years, although market intelligence

\footnotetext{
${ }^{6}$ Approaches to correct BEIRs for liquidity premium, based on relative traded volumes or asset-swap spreads for example, necessarily involve some difficult assumptions on model specification or its presence across maturities. In turn, inflation risk premium estimation usually takes place using term structure models. Estimates vary significantly across specifications even for a single country, but they generally point to significant variation in inflation risk premium over time and across maturities (see for example Federal Reserve, 2015).

${ }^{7}$ Although the index in terms of which the ECB's quantitative definition of price stability is the overall HICP, i.e. including tobacco, compliance with French regulations in the first issuance of euro area-wide inflation-linked bonds led to the choice of the euro area HICP index excluding tobacco. The latter index has become the market benchmark in the euro area since then and has been used as the reference for all the bonds indexed to euro area inflation which have been issued so far. It has also become the standard for some other financial products such as IL swaps and inflation options (caps and floors). This difference has however no material impact on our analysis and conclusions.
} 
suggests that the five and ten year maturities concentrate a significant amount of liquidity. ${ }^{8}$

We test the anchoring of inflation expectations by looking at the response of far-ahead forward inflation compensation to the announcement. If inflation expectations remain wellanchored, economic agents should believe that, once cyclical or other temporary influences fade away, the inflation rate in the euro area will return to the target of (below but close to) $2 \%$ as announced by the ECB. As such, it is logical to assume that if inflation expectations are formed from a time invariant distribution around the specified target value of the ECB, economic news about the current cyclical position of the economy should have no impact on sufficiently far-ahead forward inflation compensation.

Forward rates therefore provide a very useful means of interpreting market's inflation compensation at medium-to-long term horizons. The 5-year forward IL swap rate 5 years ahead has in particular become the most widely-used measure to assess developments in euro area long-term inflation expectations (e.g. Draghi, 2014), and it is widely used in the related literature taking for example support on the fact that standard macroeconomic models predict that inflation should return to its steady state between 5 to 10 years after a typical shock (e.g. Gürkaynak, Sack, and Swanson 2005b). The price of a spot zero-coupon swap with a 10-year maturity, $s_{t}^{10 y}$, reflects the average inflation compensation over the next ten years. Similarly for the five-year spot rate, $s_{t}^{5 y}$. In contrast, by construction, 5-year forward inflation compensation 5 years ahead, $f_{t}^{5 y 5 y}$, reflects the inflation compensation priced in between five and ten years ahead, a medium-to-long term period that captures well the movements in inflation compensation we are interested here. ${ }^{9}$ Formally, the long-term forward IL rates implicit in the term structure of IL swap rates can be calculated from the five and ten year spot rates as follows

$$
\left(1+f_{t}^{5 y 5 y}\right)=\frac{\left(1+s_{t}^{10 y}\right)^{10}}{\left(1+s_{t}^{5 y}\right)^{5}}
$$

\footnotetext{
${ }^{8}$ In our analysis we will employ daily and intraday trading information from Reuters.

${ }^{9}$ We also show that our main findings are robust to different measures of long-term inflation compensation (see Appendix for details).
} 


\section{Assessing the anchoring of inflation expectations}

\subsection{Preliminary evidence}

Before moving into the formal assessment of the reaction of long-term inflation compensation to macroeconomic news, we provide some evidence on the historical patterns between changes in inflation compensation in the days with and without macroeconomic releases in the euro area. Table 1 reports the average (absolute) daily change in long-term forward inflation compensation, $\Delta f_{t}^{5 y 5 y} \equiv f_{t}^{5 y 5 y}-f_{t-1}^{5 y 5 y}$ over four different periods. For each release, the four columns report the average daily change in the days of the release over the full sample (2005:01-2017:03), Pre-Disinflation sample (2005:01-2012:12), Pre-Disinflation sample excluding the distress market period after Lehman's collapse 2008:10-2009:06, and the BelowTarget sample (2013:01-2017:03). Finally, the last row provides the average daily change in the days without macroeconomic releases.

A few relevant insights emerge from Table 1. First, over the sample as a whole (first column), daily changes in long-term inflation compensation tend to be on average fairly similar, around 1.5 basis points, in days with and without major economic releases. Moreover, daily changes tend to be somewhat larger in the days with non-inflation releases than in those with inflation releases.

Average changes over the whole sample however mask important changes in the response of inflation compensation over time. Prior to 2013 (second column), when compared to the average changes in the days without major macroeconomic releases, changes in inflation compensation tended to be higher for non-inflation releases (both hard, e.g. the unemployment rate, and soft data releases, like PMI and other confidence indicators) than for inflation releases. The average changes presented in column 2 include the high volatility period in financial markets following the collapse of Lehman Brothers and the intensification of the financial turbulences. Abstracting from the period 15 September 2008-30 June 2009 indeed gives lower daily average changes (column 3), but does not change the overall conclusions. During the below-target period (column 4) instead changes in long-term inflation compensation have been larger in days of inflation releases (particularly for the flash estimates and the Spanish and Italian HICP which range between 1.37 to 1.92 basis points), both compared to days with no data releases (on average 1.34 basis points) and to days with non-inflation data 
releases (1.36 basis points on average).

Table 1 evidence therefore points to a shift in the reaction of inflation-market investors from macroeconomic (economic activity, confidence, etc) releases before 2013 towards inflation releases during the recent period of low inflation. We believe this is a particularly important fact for our goal in this paper. While a statistically significant reaction of long-term inflation compensation to data releases is important evidence when assessing the anchoring of inflation expectations, from a policy perspective the type of news to which they react is also important. When assessing the anchoring of inflation expectations by the impact of incoming information, the reaction to inflation news is of first-order economic significance, compared to that to business confidence indicators for example. In this regard, it is particularly noticeable that the changes in inflation compensation since 2013 have been particularly strong to the early news on inflation, particularly the first country flash estimates released (for Germany and Spain) as shown in the previous section. We search for more formal empirical evidence in the next sections.

\subsection{Evidence from daily regressions}

The empirical approach used in this paper-regressing changes in inflation compensation on the surprise component of an event or data release-belongs to a long tradition in the literature, from the early works of Roley (1982), Dwyer and Hafer (1989), Fleming and Remolona (1999) and Kuttner (2001) among others on U.S. data. However, by focusing upon forward rates as dependent variables rather than yields, and on the analysis of new indicators of inflation compensation that have become available since the early 2000s our approach is closely in spirit to Gürkaynak et al. (2005a) among others, as it allows more intuitive inference about the response of inflation compensation to new information.

Table 2 reports estimation results from the standard linear regression model (2) including all macroeconomic releases:

$$
\Delta y_{t}=\alpha+\beta \mathbf{X}_{t}+\epsilon_{t}
$$

where $t$ indexes days, and $\Delta y_{t} \equiv y_{t}-y_{t-1}$ is the one day change in the inflation swap rate over the day; $\mathbf{X}_{t}$ is a vector of macroeconomic news in data releases as described above and $\epsilon_{t}$ denotes the regression residual. The first column reports the estimated coefficients for the long-term forward IL swap rate $\left(f_{t}^{55}\right)$. The releases of the German and the Spanish flash 
estimates, as well as Industrial production, are statistically significant for long-term forward inflation compensation. Focusing on the 5-year and 10-year spot inflation compensation individually, however, many more releases have a statistically significant impact.

To gain additional evidence on the main drivers of changes in inflation compensation, we also estimate individual regressions using the surprises for individual variables focusing on the long-term forward inflation compensation $f_{t}^{55}$ and the inflation releases over different subsamples:

$$
\Delta y_{t}=\alpha+\beta \mathbf{x}_{t}+\epsilon_{t}
$$

such that $\mathbf{x}_{t}$ is a single inflation release. ${ }^{10}$

Table 3 shows that news on German and Spanish flash estimates has a significant impact over the full sample. However, subsample analysis suggests the statistical significance is mainly related to the latter part of the sample. Prior to 2013, there had been no significant reaction to inflation releases, while the reactions to surprises in flash estimates, particularly the German flash estimate, have turned strongly significant over the inflation below-target period. Moreover, the same pattern emerges if we consider a two-day window for the changes in long-term inflation compensation. ${ }^{11}$

\subsection{Evidence from time-varying regressions}

The subsample analysis in Sections 3.1 and 3.2 suggests that the effect of macroeconomic data releases on the long-term inflation compensation has most likely changed over time, and, more specifically, has strongly risen since 2013. To obtain more precise evidence on how those reactions have evolved over time equations (2) and (3) could be estimated over rolling windows. However, as most macroeconomic announcements only occur once a month, any rolling window based on individual variable release would suffer from small sample problems. We therefore provide some evidence of time-variation in the response of inflation compensation to macroeconomic releases using the approach recently introduced by Swanson and Williams (2014, SW henceforth) to study the sensitivity of long-term inflation compensation

\footnotetext{
${ }^{10}$ In early literature, stepwise regressions were run by combining surprises from different variables at daily frequency. Such regressions assigned a zero value to days with no release day for a particular variable, which is problematic in the context of event studies because a zero also defines a "no surprise" for a release by construction.

${ }^{11}$ Table A.10 in the Appendix reports regression results over a two-day window. Results also show that the reactions to the German and Spanish flashes were significant over the full sample, but again reflecting a strong significance since 2013, while they had not been significant before the below-target inflation period.
} 
to inflation news. SW introduces a set of multiplicative time dummies $\delta$ in the estimation framework, so that the overall time variation in the response of the variables of interest to macroeconomic news can then be measured by the combined effect $\delta \beta$. Such a specification therefore measures whether the response to macroeconomic news has changed over time conditional on the assumption that the sensitivity to news about all variables included in the vector of responses has changed in similar proportion. ${ }^{12}$

The SW framework suits well an analysis of a de-anchoring of inflation expectations. More specifically, SW generalizes the regression (2) to a nonlinear least squares specification of the form:

$$
\Delta y_{t}=\gamma^{\tau_{i}}+\delta^{\tau_{i}} \beta \mathbf{X}_{t}+\epsilon_{t}^{\tau_{i}}
$$

where the parameters $\gamma^{\tau_{i}}$ and $\delta^{\tau_{i}}$ are scalars that are allowed to take on different values in each calendar year $i=2005,2006, \ldots, 2017$.

To make the SW approach operational two additional assumptions are needed. First, a normalization for $\delta^{\tau_{i}}$ needs to be chosen, otherwise the model is not identified and $\beta$ cannot be properly estimated. This implies that the estimated response of long-term inflation compensation to macroeconomic news will be relative to the response over the normalization period. Following SW, we normalize $\delta^{\tau_{i}}$ to average 1 over a given period. In our baseline scenario we choose $\delta$ to be on average 1 over the period of below-target inflation 01:01:2013 31:03:2017 to unity. Intuitively, if there has been a deterioration in the anchoring of inflation expectations since 2013, by normalizing the response between 2013-17 to 1, we should observe a response of inflation compensation to macroeconomic news over the rest of our sample that is, on average, significantly below $1 .{ }^{13}$

A second assumption concerns the set of macroeconomic variables used to assess the response. Our goal in this paper is to assess the evolution of the anchoring of long-term inflation expectations in the euro area. We therefore restrict the set of variables to inflation news, for, if long-term inflation expectations react to some macroeconomic news, those about inflation, particularly unexpected low levels of inflation over a protracted downward trend since 2013, are the most relevant for our purpoase here. The empirical evidence presented above

\footnotetext{
${ }^{12}$ Figure A.7 in the Appendix contains the distribution of the surprises over different periods. The distribution is not symmetric for some macro surprises and varies across time periods. Yet, it has remained relatively contant and symmetric over time for German and Spanish flash.

${ }^{13}$ Figure A.4 in the Appendix offers results for different normalisation periods and shows that our main findings do not depend on the specific period chosen for the normalization of $\delta^{\tau_{i}}$.
} 
(Tables 1 and 2) also suggests very limited responses of long-term inflation compensation to non-inflation economic news. Furthermore, that evidence is also consistent with empirical evidence pointing at the superior performance of univariate models when forecasting inflation (see among others Faust and Wright, 2013, or in a very different context Chan et al., 2018). ${ }^{14}$ Given these considerations, our baseline specification contains six inflation data releases: the flash estimates for Germany, Spain, Italy and the euro area-wide HICP, as well as the HICP for Italy and Spain. ${ }^{15}$

The crucial value-added by the SW approach as applied here is that, by exploiting the pooling of information across inflation data releases, we can obtain more detailed evidence on the time variation in the response of long-term inflation compensation to macroeconomic news through the estimation of daily rolling regressions of the form

$$
\Delta y_{t}=\gamma^{\tau}+\delta^{\tau} \hat{\mathbf{X}}_{t}+\epsilon_{t}^{\tau}
$$

where $\hat{\mathbf{X}}_{t} \equiv \hat{\beta} \mathbf{X}_{t}$ is the generic surprise regressor defined using the estimated value of $\hat{\beta}$ from regression (4).

While $\tau_{i}$ in regression (4) refers to a specific calendar year, $\tau$ in regression (5) is yet to be specified. Focusing on a limited number of inflation data releases conditions the choice of the length of the rolling time window for $\gamma^{\tau}$ and $\delta^{\tau}$. The key motivation for regression (4) is that it allows to reduce the small-sample problem associated with allowing every element of $\mathbf{X}_{t}$ to vary over time when running rolling regressions. In equation (5) we are then pooling the information from six inflation variables together in the estimation of each scalar $\delta^{\tau}$. We define $\delta^{\tau}$ over a two year period, which allows us to estimate them over 144 observations of $\hat{\mathbf{X}}_{t}$ per time window, in line with the regressions in SW. ${ }^{16}$ Such a regression for example would be based on twice as many observations per two-year window as those used in estimation of $\beta$ over the whole pre-disinflation sample 2005-2012 in Table 3.

The two-year window also allows for identifying a weakening of inflation expectations

\footnotetext{
${ }^{14}$ Speck (2016) for example uses surprises from German and Italian business confidence as well as French manufacturing confidence. Non-inflation surprises, which rather relate to the current state of the business cycle, are arguably more relevant for the anchoring of inflation expectations in countries like the US where the Federal Reserve has to observe the double mandate of inflation stability and maximum employment than to the euro area where the ECB's target is solely defined in terms of price stability.

${ }^{15}$ Figures A.5 and A.6 in the Appendix show the time-varying $\delta^{\tau_{i}}$ using alternative HICP releases. Yet, this does not change the result qualitatively.

${ }^{16} \mathrm{SW}$ uses releases on 12 macroeconomic variables and annual calendar dummies in their analsyis of the response of U.S. nominal bond yields, which provides about 140 observations of $\hat{\mathbf{X}}_{t}$ per their year-long time window.
} 
that is sustained over a period of time, in contrast to a short-lived reaction to news that may be triggered by just a few influential data releases in a given year. The estimates of the rolling regression would therefore capture the average magnitude of the surprises over twoyear rolling windows prior to the business day $\tau$ from January 2007 through March $2017 .{ }^{17}$ This daily estimation allows for finer estimate of the variation in the responses of long-term inflation compensation over time and their comparison with the reference period. Following SW, we account for the two-stage sampling uncertainty by scaling the standard error $\sigma_{\delta^{\tau}}$ of $\delta^{\tau}$ in (5) by the weighted average of the derived standard errors of $\delta^{\tau_{i}}$ in (4). ${ }^{18}$

Figure 3 depicts the $\delta^{\tau_{i}}$ estimates from daily regressions together with their uncertainty bands. There are three main insights on the sensitivity of long-term inflation compensation to macroeconomic news. ${ }^{19}$ First, there is significant variation of the responses between 2005 and 2017, which points to substantial fluctuations in the degree of anchoring of inflation expectations during the existence of the euro area. Second, the sensitivity of inflation compensation has been particularly high (in relative terms) since euro area inflation has remained below-target, being close to and most of the time above 1 since 2014 and increasing sharply from a level statistically not different from zero since the start of the GFC.

[Figure 3 around here]

Finally, our results also identify a sharp deterioration in the anchoring of inflation expectations in the second half of 2008. This is consistent with the substantial increase in oil prices, actual inflation and inflation compensation over 2008 ahead of the collapse of Lehman Brothers. The results depicted in Figure 3 suggest that the 2008 episode was rather short-lived, but the period 2008-2009 should be interpreted with caution because euro area inflation markets

\footnotetext{
${ }^{17}$ The subsample analysis in previous section points to an increase in the impact of inflation news since 2013. We look for supporting evidence by assessing the responses on rolling regressions over one-sided windows while SW report results over two-sided windows centered around the business date.

${ }^{18}$ Specifically, we calculate the adjusted $\sigma^{\tau}$ as $\sigma_{a d j}^{\tau}=\sigma^{\tau}\left(\sum_{i}^{I_{\tau}} w_{i} \zeta^{\tau_{i}}\right)$ where the set $I_{\tau}$ specifies the calendar years the rolling window covers and $w_{i}$ is equivalent to the number of days in calendar year $i$ devided by the total number of days of rolling window $\tau$.

${ }^{19}$ We also replicate SW's statistical tests for several additional dimensions of the time variation in the responses of long-term inflation compensation to news. Test details are reported in Table A.5 in the Appendix. First, we test whether the relative response coefficients $\beta$ in regression (4) are constant over time (only $\delta^{\tau_{i}}$ varies) against an alternative in which every element of $\beta$ varies. With $p$-values close to 1 our data is consistent with the restricted specification of (4). Second, we test the hypothesis that the $\delta^{\tau_{i}}$ in (4) are the same for positive and negative surprises. Releases are split into positive and negative values of $\beta \mathbf{X}$ in each calendar year and test if $\delta^{\tau_{i}}$ is the same across all the years. With a value close to one symmetry is clearly accepted by the 5y5y. Third, we test the hypothesis that the time-varying coefficient $\delta^{\tau_{i}}$ is constant over time that is for each calendar year $i=2005, \ldots, 2017 \delta^{\tau_{i}}=1$. With low $p$-value across the data clearly rejects this restriction for the $5 y 5 y$.
} 
were under significant stress then, and it cannot be ruled out that the stronger sensitivity to news may just be the result of higher volatility of inflation compensation measures at the time. Indeed, there is a significant widening of uncertainty in the estimation around that time and $\delta^{\tau}$ becomes statistically insignificant despite its relatively high level.

Overall, the time-varying regressions point to a deterioration in the anchoring of euro area inflation expectations since 2013. While our findings are robust to different normalization periods and the inclusion of different inflation releases in the analysis, ${ }^{20}$ it is also true that their estimation requires nonetheless pooling together a number of variables. The next section provides additional evidence on the responses to news on specific data releases.

\subsection{Evidence from intraday data analysis}

We expand existing analysis on the reaction of euro area inflation expectations to news by conducting regressions using high frequency (intraday) data. Arguably event-study analysis, as the one conducted in previous sections and the related literature, is preferably undertaken with intraday data: since in a small enough window around the news arrival, nothing other than the news under investigation should be affecting asset prices, that would make the event study resemble as close as possible a controlled natural experiment (Gürkaynak and Wright, 2013). In this vein, intraday market movements offer additional evidence on the reaction of long-term inflation compensation to inflation data releases.

We collect intraday trades of euro area IL swap rates from Reuters. Using the specific time of the data release as reported in Bloomberg, we consider the changes in the spot and forward inflation compensation over two different windows, 15 minutes and 120 minutes after the data release. All the main macroeconomic releases used in our analysis take place during standard trading hours for the euro area IL swap market.

The key advantage of data on intraday trading is that over those two windows, at least on our sample, there are no important additional releases that interfere with the market trading of inflation compensation, and therefore the changes should be directly attributable to the specific data release under study. Regrettably, a shortcoming of our high frequency data is that their collection is only available from late 2008. While we cannot use our intraday data sample to investigate the anchoring of inflation expectations prior to the GFC, we can

\footnotetext{
${ }^{20}$ See Figures A.4 to A.6 in the Appendix.
} 
however assess the reaction of inflation compensation measures in the most important period, namely the severe disinflation that took place in the euro area since 2013.

Intraday evidence corroborates our previous findings of a deterioration of the anchoring of long-term inflation expectations in the later part of our sample. Between 2013-2017, over a 120 minute window from the data release long-term inflation compensation has significantly reacted to the news component of the flash releases for Germany and Spain, as well as of the Spanish HICP (see Table 4). Moreover, those reactions have been strongly significant (even at $1 \%$ significance level). Over a shorter time window of 15 minutes, the reaction is somewhat more muted, but nonetheless statistically significant for the German flash and also the euro area flash estimate.

Furthermore, the time-varying reaction estimated in the previous section points to a protracted deterioration in the reaction of long-term inflation compensation to inflation news since the second half of 2014. Such a deterioration took place following a sharp increase in significance between late 2008-early 2009, a highly turbulent period in financial markets over which it is difficult to draw firm conclusions from the IL swap market. Yet, intraday data estimates from the second half of 2009 until the end of 2012 do not show any evidence of significant reactions of long-term inflation compensation to inflation news: the estimated responses to all the flash estimates and HICP releases are statistically insignificant at both the 15 and 120-minute windows. Intraday analysis therefore provides strong support to the importance of early releases, as well as the presence of a weakening of the anchoring in inflation expectations since 2013.

\section{Discussion}

Previous sections have reported our main findings on the response of long-term inflation compensation to inflation and macroeconomic news in the euro area. Three different but complementary pieces of analysis, namely daily, time-varying and intraday regressions, provide robust evidence of a weakening of the anchoring of euro area long-term inflation expectations since 2013. This section highlights some additional dimensions of our findings, and discusses them in the context of related evidence. 


\subsection{The importance of the timing of macroeconomic and inflation news}

Our findings are strongly related to a fundamental topic in the financial literature on price formation: how fast do market participants incorporate (macroeconomic) news in their pricing decisions? There is substantial evidence that news released earlier in time tend to have a greater impact on financial assets than news about the same variable released later (e.g. Fleming and Remolona, 1997, Andersen et al., 2003).

The timing of macroeconomic releases has not been emphasized in the literature on the reaction of inflation expectations to news. In most countries, for example in the large number of studies employing U.S. data, inflation news is usually coming from at most two variables, namely CPI and PPI indices. The relevant flow of inflation news in the euro area is instead much richer as a result of both its comprising a large number of countries and the releases of flash estimates (advanced) for several of them (Germany, Spain, Italy and more recently also France), in addition to the euro area-wide aggregate. While the bulk of the euro area market for IL products are linked to the euro area-wide inflation, inflation news at country-specific level does matter. Indeed, our results offer additional evidence in support for a fast pricing of news in modern financial markets: inflation news from earlier releases (even if at country level like the flash estimates for Germany and Spain) tends to lead to stronger market reactions than later releases.

The relevance of timeliness versus precision of macroeconomic news on the asset price response has been recently been explored in Gilbert et al (2017) and in Hess and Niesen (2010) among others. Both studies find that financial markets favor timeliness to preciseness of macroeconomic data. To investigate the heterogeneous response of Treasury bond futures to macroeconomic news Gilbert et al (2017) estimate the intrinsic value of a macroeconomic announcement (defined as the ability to nowcast GDP growth, inflation, and the Federal Funds Target Rate), and decompose that intrinsic value into its relation to fundamentals, its timing, and its revision noise. They find that over recent years the part of the intrinsic value of the release closely related to its timing is the most important characteristic behind its asset price impact. Exploring those characteristics is beyond the scope of this paper, but our findings regarding the impact of the flash estimates for HICP over the more comprehensive, but delayed release of the HICP, fully corroborates the insights from Gilbert et al (2017).

Similarly, Hess and Niesen (2010) argue that there is trade-off between early availability 
and information quality. Using a sequential Bayesian learning model, they test the existence of that trade-off using two similar but sequentially introduced German economic indicators: ZEW (earlier release) and IFO indicators (higher quality). As predicted by their theoretical Bayesian model, they find that the ZEW has greater market impact due to its earlier release. Further evidence on the importance of the timing of news can be found in Hess (2004), which studies the impact of large and diverse set of macroeconomic announcements using high-frequency analysis and finds that the response to announcements that are released in month $m+1$ is significantly stronger than the impact of announcements released a month later $(m+2)$.

\subsection{What is behind the reaction of inflation compensation?}

Inflation compensation comprises both a level of long-term inflation expectations and an additonal inflation risk premium that investors request to bear the risks surrounding those inflation expectations over the length of the investment. As argued above, both components reflect the pricing of different dimensions of anchoring, and are therefore very relevant from a monetary policy point of view. Yet, evidence of a statistically significant reaction of long-term forward inflation compensation to news could be the result of a change in the level of inflation expectations, or in the risks surrounding that level priced in as inflation risk premia. While it is difficult to disentangle these two components, we argue that the sensitivity of far-forward inflation compensation to macroeconomic news since 2013 is indicative of a weaker anchoring of inflation expectations. In this section we use additional information from survey data to discuss whether that weakening may reflect changes in expected inflation, in the inflation risk premium, or both.

Figure 1 above provides some graphical evidence on the behavior of private sector's inflation expectations over recent years. Specifically it depicts the long-term forward IL swap rate (five-year forward in five years) together with two survey measures of long-term inflation expectations, from Consensus Economics (6 to 10 years ahead) and from the ECB's Survey of professional Forecasters (SPF) (five-years ahead, ECB's SPF). ${ }^{21}$

Long-term forward inflation compensation have declined significantly in the euro area since actual inflation rates started to decline and surprise negatively since 2013. Such a

\footnotetext{
${ }^{21}$ For an introduction to the ECB's SPF see García (2003).
} 
decline was not exclusive to the euro area, and attracted substantial attention among policymakers (Draghi, 2014, 2015, 2017; Yellen, 2015), as well as in specialized press and market commentary (e.g. The Economist, 2014; Financial Times, 2016). Survey measures of inflation expectations have in contrast remained relatively more stable in the euro area, but a decline away from the (below but close to) $2 \%$ target level of the ECB can also be observed since mid-2013.

We interpret this evidence as pointing to a decline in the level inflation expectations embodied in long-term inflation compensation measures, above and beyond a potential decline in the inflation risk premia. ${ }^{22}$ Garcia and Poon (2018) shows that (long-term) trend inflation has declined since 2013, with the estimates significantly below the $2 \%$ mark between 201417 , a finding that is robust to both market-based and survey measures of long-term inflation expectations.

Furthermore, it is important to note that our analysis of inflation compensation does not rely on the expectations theory of the term structure. Since inflation compensation captures the compensation that investors demand both for expected inflation and for the risks or uncertainty associated with that inflation at that horizon, changes in long-term forward IL swap rates need not be due solely to shifts in the conditional mean of inflation rate expected at long horizons: if the anchoring of inflation expectations weakens, then economic news might well shift the far-ahead forward inflation risk premium, either because near-term economic developments affect investors' perceptions regarding the distribution of long-run inflation outcomes, or because the economic news has a significant impact on the price that investors attach to those long-run inflation risks.

\subsection{Related literature}

Over the last decade, there has been a substantial interest in assessing the anchoring of inflation expectations in the euro area using the sensitivity of long-term inflation compensation measures to macroeconomic news. In this paper we use a longer sample, a richer set of infla-

\footnotetext{
${ }^{22}$ Term structure models regularly monitored by Federal Reserve or the ECB point to a compression in inflation risk premium in the U.S. and the euro area, but cannot fully explain the decline of long-term inflation compensation measures (e.g. Federal Reserve, 2015). Information on investors' risk perceptions obtained from the pricing of inflation options -inflation caps (floors) offer compensation whenever inflation is higher (lower) that the specified strike price- also actively traded in the U.S. and euro area markets corroborate the presence of significant concerns about low inflation levels even at long horizons among market participants over recent years (e.g Gimeno and Ibañez, 2017).
} 
tion news, and a more comprehensive empirical analysis than most existing literature, which leads to results that often corroborate, but in some cases also qualify, some of the previous findings. We discuss them in turn below.

Empirical evidence using sample data before the GFC has been broadly supportive of a firm anchoring of inflation expectations in the euro area (e.g. Coffinet and Frappa, 2008, Beechey et al., 2011, Ehrmann et al., 2011). Overall, no evidence of a significant reaction of long-term inflation compensation in the euro area is found, looking at different forward inflation compensation measures and long-term nominal interest rates, and somewhat different inflation news. ${ }^{23}$ Most studies before the GFC mainly focused on international comparison, and the lack of significant responses was generally attributed to the ECB's credibility, underpinned by the announcement of a quantitative inflation target and its determination to meet that target over the medium term. Indeed, euro area inflation expectations have been often found to be more strongly anchored than in other countries like the U.S., the U.K. or Sweden (e.g. Gürkaynak, Levin, and Swanson, 2010). Related literature has also investigated the news reactions in some inflation-targeting countries that have issued inflation-linked bonds (see De Pooter et al., 2014 for Brazil, Chile, and Mexico and Gürkaynak et al., 2007, for Canada, Chile and the US), thereby stressing the crucial role of the monetary policy framework in the anchoring of inflation expectations. Our analysis employs a richer set of inflation news, including the country flash estimates, and also corroborates the main findings of those studies, both using the benchmark 5 -year forward IL rate in 5 years $\left(f_{t}^{5 y 5 y}\right.$, see Section 3) and, as additional robustness check, the 1-year forward IL rate in 9 years used in some existing literature $\left(f_{t}^{1 y 9 y}\right.$, see Table A.9 in the Appendix).

Interest on a reassessment of the anchoring of inflation expectations surged in response to the GFC. A new wave of papers revisited this issue in an international context by extending the samples to the GFC period (e.g. Galati et al., 2011, Autrup and Grothe, 2014). ${ }^{24}$ Those

\footnotetext{
${ }^{23}$ Coffinet and Frappa (2008) test the 5-year forward IL rate in 5 years (our benchmark measure) against euro area flash estimate and country-specific HICP releases as well as various other macro announcements. Beechey et al (2011) test for the 1-year forward IL rate in 9 years and similarly use country-specific HICP and other macroeconomic releases but they do not consider flash estimates. Ehrmann et al (2011) instead compare the mean and variance of 1-year forward nominal interest rates in 9 years in the yield curves of euro area countries prior to and during the single currency period, and interpret the decline and convergence of both moments across countries as signalling a stronger anchoring of inflation expectations.

${ }^{24}$ Galati et al. (2011) use a sample from June 2004 until March 2009 for the U.S., the euro area and the U.K., and find that euro area and UK inflation expectations seem to be more stable compared to those in US. To gauge the reaction of inflation compensation they only use country-specific HICP releases as inflation news and found that the VIX has a statistically significant impact on expectations. Autrup and Grothe (2014) stretch the crisis sample to 2012 and compare US and EA expectations to find the latter more stable. They
} 
studies explicitly acknowledge that the analysis in the aftermath of the Lehman collapse years is subject to some uncertainty given the extreme market volatility and limited liquidity during the financial crisis period. Accounting for those market distortions by introducing additional controls in their regressions (e.g. VIX, bond market volatility, oil prices, etc), they tend to find evidence consistent with the anchoring of euro area long-term inflation expectations remaining strong after the GFC.

Our results also suggest that the anchoring of euro area inflation expectations remained resilient to the GFC. The analysis in this paper offers an additional perspective on the impact of the GFC by providing evidence on the changes in the sensitivity of long-term inflation compensation through time-varying regressions (Section 3.3). In this regard, the sharp rise in the uncertainty surrounding our time-varying estimates in late 2008 suggests that caution is needed when interpreting the results for that period: we interpret that surge in uncertainty as fully consistent with the presence of a significant market volatility and liquidity risk, as reported in Galati et al. (2011) and Autrup and Grothe (2014). Moreover, we also show that our main empirical findings both over our whole sample and in specific subsamples are robust to the addition of a significant number of controls in the regressions (see Tables A.6 to A.8 in the Appendix for additional results).

In the light of the weak inflation dynamics since 2013, and the launching of additional UMP measures by the ECB in 2015, the interest on the reaction of inflation compensation to macroeconomic news has gained momentum again. A challenge for this line of research is that, for a weaker anchoring of euro area inflation expectations to be economically meaningful, it has to be sustained over a certain period of time. A minimum sample is therefore required to reach robust conclusions. To ascertain whether the anchoring has weakened it is also important to check the extent to which the observed reactions are significantly different from those observed in the past.

The more recent stream of research have looked at short-term maturities and also different IL instruments. Miccoli and Neri (2015) for example looks at the reaction of IL swap spot and forward rates at various maturities (including the short run) to the euro area HICP releases comparing the average of 10 business days prior to and after the date of release. Speck (2016) jointly regresses the 2-year spot, the 3 -year forward in 2 years and the 5 -year forward in 5 years also show that their measure of inflation compensation, based on bond-based evidence rather than IL swaps, is statistically influenced by a liquity risk premium. 
together, tests for the reaction to news through a Wald test on the regression coefficients, and investigates the time-variation in the sensitivity to news along the lines we used in Section 3 using both country flash estimates and also confidence indicators. Both studies show some evidence of a stronger sensitivity of medium-to-long-term inflation compensation to news over recent years, but disagree on whether that evidence is sufficiently conclusive for the presence of a significant de- anchoring of inflation expectations, or just a longer-than-normal correction from low inflation levels. Pagenhardt, Nautz and Strohsal (2017) instead provides evidence of a de-anchoring of euro area inflation expectations since September 2011 based on structural break tests (Bai, 1997, and Bai and Perron, 1998). Their study is based on the reaction of the risk-adjusted bond-based 5-year forward break-even inflation rates in 5 years to the euro area HICP and some other macroeconomic data releases.

Other recent studies have looked for additional evidence from the euro area inflation options market, a financial instrument more recently (since 2009) added to the inflation derivatives universe. ${ }^{25}$ Galati et al. (2016) investigates the reaction the deflation risk implied by risk-neutral densities (RNDs) on year-on-year inflation to oil price changes, and find evidence consistent with a subtle, but nonetheless statistically significant, weakening in the anchoring of long-term inflation expectations. Gimeno and Ibañez (2017) estimate inflation RNDs using IL swap and inflation options (caps and floors) across a large number of horizons-including at the 5 -year forward in 5 years benchmark reference for monetary policy - and finds that the priced probability associated to negative inflation values at that long horizon, after declining from 2012, rose significantly again from early 2014 and almost double in less than two years to around $12 \%$ (above $30 \%$ at the 2 -year forward in 2 years). While those probabilities may not appear to be very high, their pricing at fairly long horizons suggests that they do not reflect just temporary factors, which is consistent with a weakening of the anchoring of euro area long-term inflation expectations since 2013.

Using a longer sample and in many cases a richer set of inflation news, and the insights of novel evidence from intraday data, the evidence presented in Section 3 adds additional robustness to the finding of a weakening in the anchoring of euro area inflation expectations

\footnotetext{
${ }^{25}$ Inflation options in similar fashion to standard (European) options for stocks or interest rates provide financial protection when inflation, the underlying asset in their case, moves above or below (cap and floor options, respectively) a given threshold (i.e. the strike price or rate). As in the case of ILS, inflation option are actively traded over-the-counter and their market is more developed in the euro area than in most other countries (Smith, 2012).
} 
after 2013. Furthermore, literature employing different empirical approaches are also consistent with our findings. For example Łyziak and Paloviita (2017) test the sensitivity of long-term inflation expectations to changes in short-term ones using survey data. Survey data do not incorporate inflation risk premia, and offer a somewhat longer history (since the start of the euro area in 1999) but at much lower frequencies (quarterly), which make them somewhat less appropriate for identifying changes over time. Nonetheless, splitting the sample at the second quarter of 2008, Eyziak and Paloviita (2017) evidence points to a deanchoring of long-term inflation expectations based on the significant impact of short-term expectations on longer term ones over the second part of their sample. García and Poon (2018) estimate euro area (long-term) trend inflation using actual inflation developments and different measures of long-term inflation expectations, including surveys, and show that there has been a significant decline below the $2 \%$ level in euro area trend inflation since 2013, consistent with a de-anchoring of inflation expectations.

\section{Conclusions}

Following the unprecedented period of low (and below-target) inflation in the euro area since 2013, whether the anchoring of euro area inflation expectations has weakened in recent years is a crucial question. The monetary transmission mechanism is most effective when longterm inflation expectations are strongly anchored, and indeed evidence on earlier samples has found that euro area inflation expectations were well-anchored around the ECB's quantitative definition of price stability of (below but close) to $2 \%$. Yet, more than three years after the launching of the Eurosystem's Asset Purchase Programme in early 2015, inflation remains low and there is still need for ample degree of monetary stimulus for underlying inflation pressures to continue to build (Draghi, 2018).

This paper finds evidence of a weakening in the anchoring of inflation expectations in the euro area since 2013. We tested the sensitivity of long-term inflation compensation to inflation and macroeconomic news in line with existing literature. We expand the standard analysis to all available early inflation releases for country and euro area-wide inflation, and investigate the reactions of long-term inflation expectations by means of daily, time-varying and intraday regressions to add robustness to our conclusions. Our results point to a significant impact of inflation news over recent years that had not been observed before. 


\section{References}

Andersen, T.G., Bollerslev, T., Diebold, F.X. and Vega, C. (2003) 'Micro Effects of Macro Announcements: Real-Time Price Discovery in Foreign Exchange', The American Economic Review 93 (1), pp. 38-62.

Autrup, S.L. and Grothe, M. (2014) 'Economic surprises and inflation expectations: Has anchoring of expectations survived the crisis?', European Central Bank Working Paper Series (1671).

Bai, J. (1997) 'Estimating Multiple Breaks One at a Time', 13 (3), pp. 315-352.

Bai, J. and Perron, P. (1998) 'Estimating and Testing Linear Models with Multiple Structural Changes', Econometrica 66 (1), pp. 47-78.

Bartsch, E., Antonucci, D., Bizimana, O., Baker, M., Ashworth, J. and Gedal, M. (2014) 'A Practitioner's Guide to European Macro Indicators', Morgan Stanley.

Beechey, M.J., Johannsen, B.K. and Levin, A.T. (2011) 'Are Long-Run Inflation Expectations Anchored More Firmly in the Euro Area Than in the United States?', American Economic Journal: Macroeconomics 3 (2), pp. 104-29.

Bernanke, B. (2007) FED Press Conference.

Bernanke, B.S. and Boivin, J. (2003) 'Monetary policy in a data-rich environment', Journal of Monetary Economics 50 (3), pp. 525-546.

Chan, J.C.C., Clark, T.E. and Koop, G. (2018) 'A New Model of Inflation, Trend Inflation, and Long-Run Inflation Expectations', Journal of Money, Credit and Banking 50 (1), pp. $5-53$.

Coffinet, J. and Frappa, S. (2008) 'Macroeconomic Surprises and the Inflation Compensation Curve in the Euro Area', Banque de France Working papers (220).

Coibion, O. and Gorodnichenko, Y. (2015) 'Information Rigidity and the Expectations Formation Process: A Simple Framework and New Facts', American Economic Review 105 (8), pp. $2644-78$.

Draghi, M. (2014) 'Unemployment in the euro area', Annual central bank symposium in Jackson Hole, August 22.

Draghi, M. (2015) ECB Press Conference, January 22.

Draghi, M. (2018) ECB Press Conference, April 26.

Dwyer, G.P. and Hafer, R.W. (1989) 'Interest rates and economic announcements', Review (Mar), pp. 34-46.

Ehrmann, M., Fratzscher, M., Gürkaynak, R.S. and Swanson, E.T. (2011) 'Convergence and Anchoring of Yield Curves in the Euro Area', The Review of Economics and Statistics 93 (1), pp. 350-364.

Eurostat (2017) 'Inflation: methodology of the euro area flash estimate', Statistics Explained.

Faust, J. and Wright, J.H. (2013) 'Forecasting Inflation', vol. 2, Elsevier, chap. Chapter 1, pp. $2-56$.

Federal Reserve, Board of Governors (2015) 'Challenges in interpreting measures of longerterm inflation expectations', Monetary Policy Report, 24 February.

CInternational Monetary Fund. Not for Redistribution 
Financial Times (2016) 'Eurozone inflation expectations hit record low', 13 June.

Fleming, M.J. and Remolona, E.M. (1997) 'What moves the bond market?', Economic Policy Review (Dec), pp. 31-50.

Fleming, M.J. and Remolona, E.M. (1999) 'Price Formation and Liquidity in the U.S. Treasury Market: The Response to Public Information', Journal of Finance 54 (5), pp. 19011915 .

Galati, G., Poelhekke, S. and Zhou, C. (2011) 'Did the Crisis Affect Inflation Expectations?', International Journal of Central Banking 7 (1), pp. 167-207.

Galati, G., Gorgi, Z., Moessner, R. and Zhou, C. (2016) 'Deflation risk in the euro area and central bank credibility', DNB Working Papers (509).

García, J.A. (2003) 'An introduction to the ECB's Survey of Professional Forecasters', European Central Bank Occassional Paper Series (7).

García, J.A. and Manzanares, A. (2007) 'Reporting biases and survey results: evidence from European professional forecasters', European Central Bank Working Paper Series (836).

García, J.A. and Poon, A. (2018) 'Trend inflation and inflation compensation', IMF Working paper, forthcoming.

Gilbert, T., Scotti, C., Strasser, G. and Vega, C. (2017) 'Is the intrinsic value of macroeconomic news announcements related to their asset price impact?', Journal of Monetary Economics 92, pp. 78-95.

Gimeno, R. and Ibañez, A. (2017) 'The eurozone (expected) inflation: an option s eyes view', Banco de Espana Working Papers (1722).

Gürkaynak, R.S., Levin, A. and Swanson, E. (2010) 'Does Inflation Targeting Anchor LongRun Inflation Expectations? Evidence from the U.S., UK, and Sweden', Journal of the European Economic Association 8 (6), pp. 1208-1242.

Gürkaynak, R.S., Sack, B. and Swanson, E. (2005a) 'Do Actions Speak Louder Than Words? The Response of Asset Prices to Monetary Policy Actions and Statements', International Journal of Central Banking 1 (1).

Gürkaynak, R.S., Sack, B. and Swanson, E. (2005b) 'The Sensitivity of Long-Term Interest Rates to Economic News: Evidence and Implications for Macroeconomic Models', American Economic Review 95 (1), pp. 425-436.

Gürkaynak, R.S. and Wright, J.H. (2013) 'Identification and Inference Using Event Studies', Manchester School 81, pp. 48-65.

Gürkaynak, R., Levin, A.T., Marder, A.N. and Swanson, E.T. (2007) 'Inflation targeting and the anchoring of inflation expectations in the western hemisphere', Economic Review, pp. 25-47.

Hess, D. (2004) 'Determinants of the relative price impact of unanticipated information in U.S. macroeconomic releases', Journal of Futures Markets 24 (7), pp. 609-629.

Hess, D. and Niessen, A. (2010) 'The early news catches the attention: On the relative price impact of similar economic indicators', Journal of Futures Markets 30 (10), pp. 909-937.

Kuttner, K.N. (2001) 'Monetary policy surprises and interest rates: Evidence from the Fed funds futures market', Journal of Monetary Economics 47 (3), pp. 523-544. 
Łyziak, T. and Paloviita, M. (2017) 'Anchoring of inflation expectations in the euro area: Recent evidence based on survey data', European Journal of Political Economy 46, pp. 5273.

Miccoli, M. and Neri, S. (2015) 'Inflation surprises and inflation expectations in the euro area', Questioni di Economia e Finanza (Occasional papers), Banca d Italia (265).

Nautz, D., Pagenhardt, L. and Strohsal, T. (2017) 'The (de-)anchoring of inflation expectations: New evidence from the euro area', The North American Journal of Economics and Finance 40, pp. 103-115.

Pooter, M.D., Robitaille, P., Walker, I. and Zdinak, M. (2014) 'Are Long-Term Inflation Expectations Well Anchored in Brazil, Chile, and Mexico?', International Journal of Central Banking 10 (2), pp. 337-400.

Roley, V.V. (1982) 'The Effect of Federal Debt-Management Policy on Corporate Bond and Equity Yields', The Quarterly Journal of Economics 97 (4), pp. 645-668.

Smith, T. (2012) 'Option-implied probability distributions for future inflation', Bank of England Quarterly Bulletin 52 (3), pp. 224-234.

Speck, C. (2016) 'Inflation anchoring in the euro area', Deutsche Bundesbank Discussion Papers $(04 / 2016)$.

Swanson, E.T. and Williams, J.C. (2014) 'Measuring the Effect of the Zero Lower Bound on Medium- and Longer-Term Interest Rates', American Economic Review 104 (10), pp. 3154-85.

The Economist (2014) 'The dangers of deflation: the pendulum swings to the pit', 25 October.

The Economist (2017) 'Inflation: a welcome revival', 14 January.

Yellen, J. (2015) FED Press Conference. 
Figure 1: Actual inflation, market-based and survey long-term inflation expectations

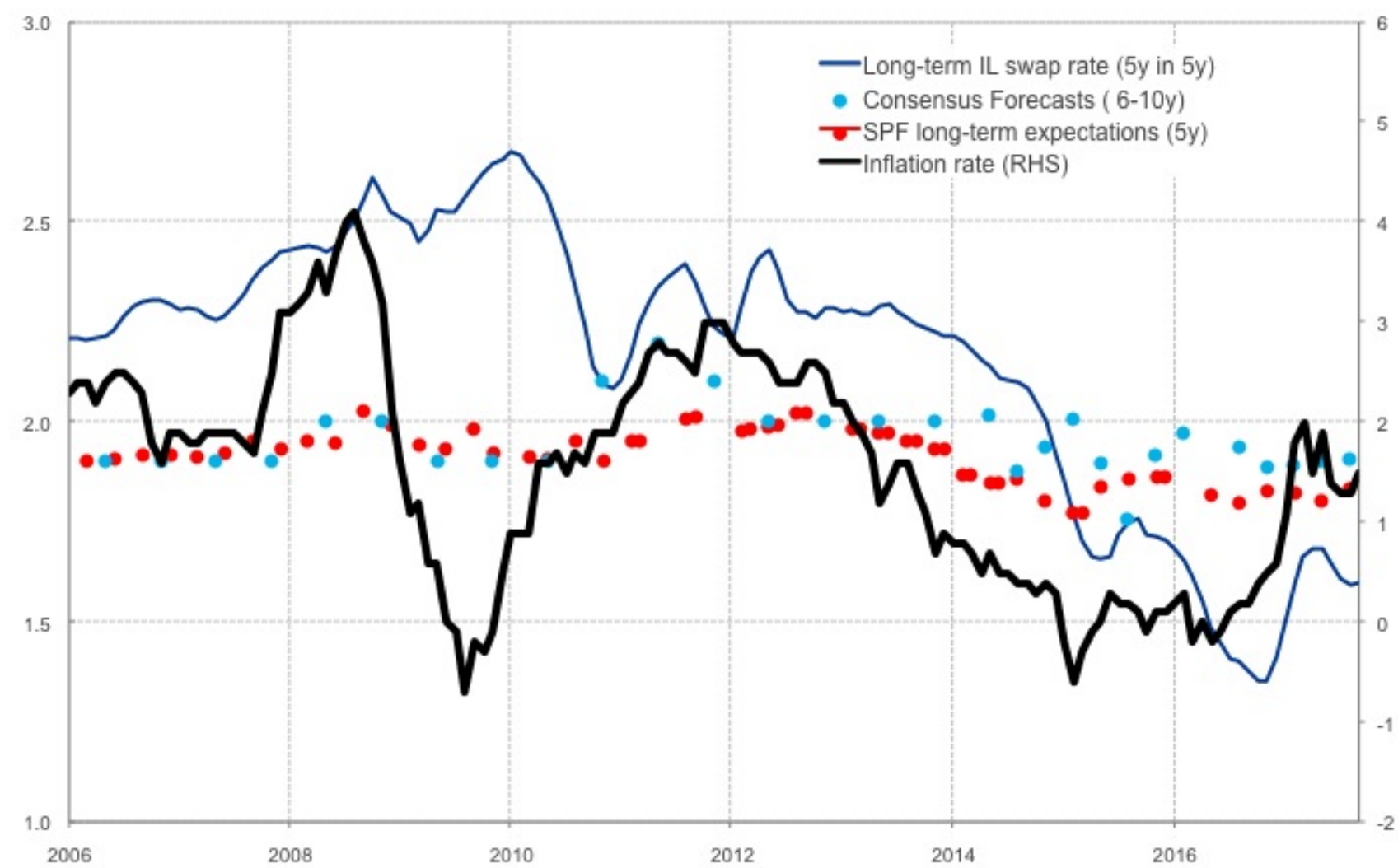

Notes: The figure shows developments in the main indicators of long-term inflation expectations and the actual year-on-year rates of inflation in the euro area. Specifically, it depicts 5-year forward inflationlinked swap rate in 5 years (thin blue line); 6-10 years Consensus Forecasts (blue dots) and 5 year ahead expectations from the ECB's Survey of Professional Forecasters (red dots) and the realized inflation rate (thick black line). 
Figure 2: Schedule of Flash and HICP inflation data releases

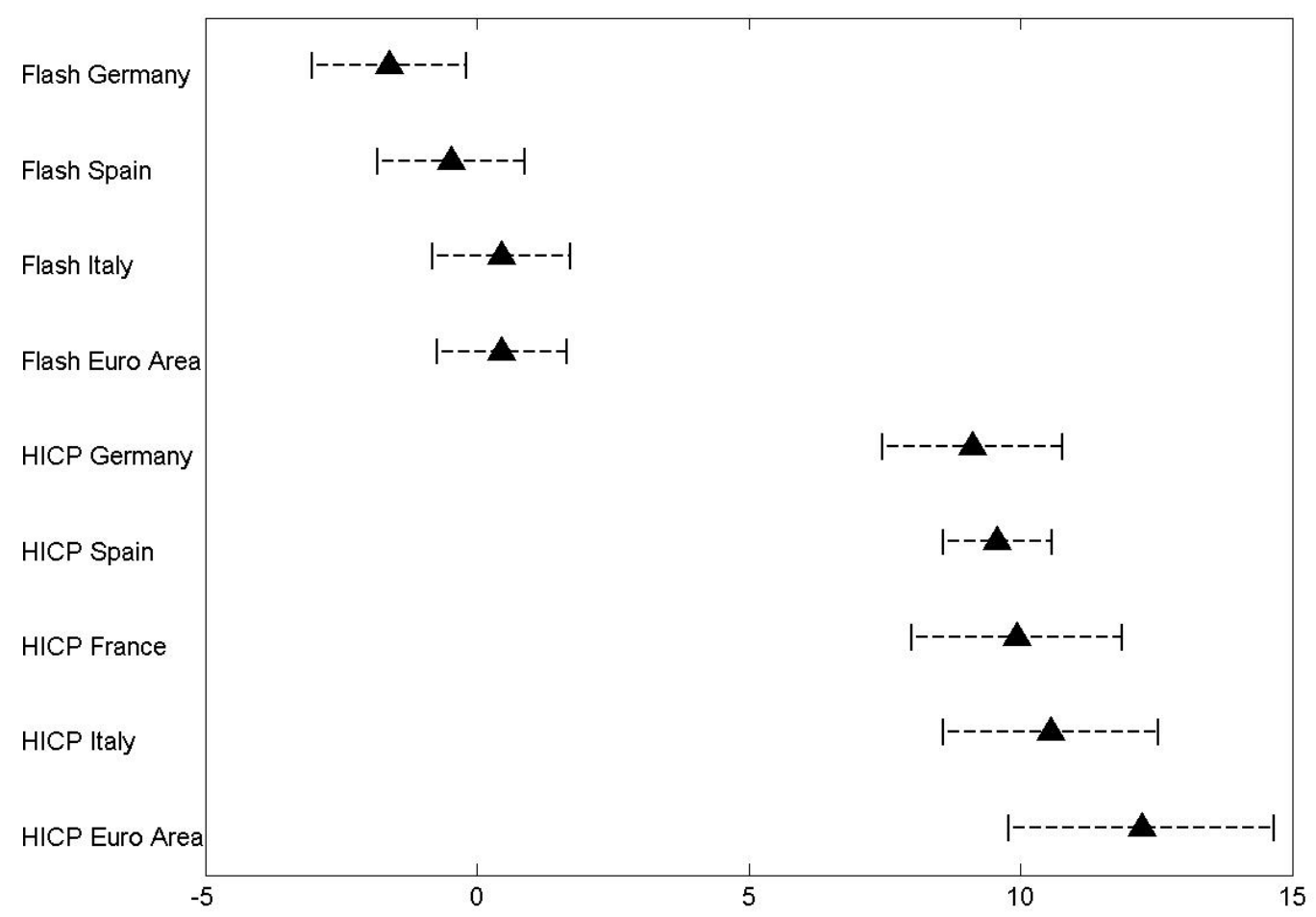

Notes: The figure shows the average calendar timing of flash and HICP data releases for European countries (Germany, Spain, France and Italy) and euro area wide inflation. The y-axis lists inflation releases, $\mathrm{x}$-axis indicates the average release days (triangle) and whiskers reflect the distribution over our sample (01:2005 to 03:2017). 0 denotes the last business day of the month to which the release refers; 5 denotes 5 business days after the last business day of the month etc. For example the Flash HICP for Germany was released on average 2 days before the last business day of the corresponding month and the HICP release for Italy on average more than 10 working days into the following month. 
Table 1: Daily changes in EA inflation long-term compensation around data releases

\begin{tabular}{|c|c|c|c|c|}
\hline $\begin{array}{l}\text { Sample } \\
\text { Period }\end{array}$ & $\begin{array}{c}\text { Full } \\
(01: 2005-03: 2017)\end{array}$ & $\begin{array}{l}\text { Pre-Disinflation } \\
(01: 2005-12: 2012)\end{array}$ & $\begin{array}{c}\text { Pre-Disinflation } \\
(01: 2005-12: 2012) \\
\text { (Excl. Lehman) }\end{array}$ & $\begin{array}{c}\text { Below Target } \\
(01: 2013-03: 2017)\end{array}$ \\
\hline \multicolumn{5}{|l|}{ Flashes } \\
\hline Germany & 1.64 & 1.56 & 1.27 & 1.79 \\
\hline Spain & 1.57 & 1.38 & 1.19 & 1.92 \\
\hline Italy & 1.46 & 1.50 & 1.33 & 1.39 \\
\hline Euro Area & 1.42 & 1.47 & 1.30 & 1.32 \\
\hline Average & 1.52 & 1.48 & 1.27 & 1.60 \\
\hline \multicolumn{5}{|l|}{ HICP } \\
\hline Germany & 1.33 & 1.42 & 1.38 & 1.18 \\
\hline Spain & 1.49 & 1.55 & 1.30 & 1.37 \\
\hline France & 1.31 & 1.32 & 1.09 & 1.29 \\
\hline Italy & 1.55 & 1.62 & 1.48 & 1.40 \\
\hline Euro Area & 1.40 & 1.54 & 1.42 & 1.13 \\
\hline PPI & 1.56 & 1.63 & 1.55 & 1.42 \\
\hline Average & 1.44 & 1.51 & 1.37 & 1.30 \\
\hline \multicolumn{5}{|c|}{ Other macroeconomic announcements } \\
\hline GDP & 1.37 & 1.42 & 1.31 & 1.26 \\
\hline PMI & 1.56 & 1.74 & 1.58 & 1.25 \\
\hline Consumer Confidence & 1.54 & 1.58 & 1.49 & 1.46 \\
\hline Industrial Confidence & 1.62 & 1.64 & 1.52 & 1.58 \\
\hline Industry production & 1.45 & 1.52 & 1.30 & 1.31 \\
\hline New Orders & 1.63 & 1.63 & 1.45 & \\
\hline Unemployment rate & 1.69 & 1.91 & 1.67 & 1.25 \\
\hline M3 & 1.44 & 1.38 & 1.26 & 1.54 \\
\hline Retail sales & 1.56 & 1.58 & 1.39 & 1.30 \\
\hline Trade balance & 1.63 & 1.81 & 1.71 & 1.31 \\
\hline Average & 1.55 & 1.62 & 1.47 & 1.36 \\
\hline No News & 1.52 & 1.59 & 1.44 & 1.34 \\
\hline
\end{tabular}

Notes: The table reports the average changes of EA inflation long-term compensation ( $f_{t}^{5 y 5 y}$ forward rate) on days of data releases. The last row reports the average response on days in which no relevant data are released. Pre-Disinflation (Excl. Lehman) excludes the 9 months (2008:10-2009:06) after the collapse of Lehman Brothers, due to the exessive volatility market data in general, and in particular for inflation compensation during these months for inflation compensation over these months. 
Table 2: Daily regression: Coefficient Estimates $\beta$ from Linear Regression

\begin{tabular}{|c|c|c|c|c|c|c|c|}
\hline \multirow[b]{2}{*}{ Flash } & \multirow[b]{2}{*}{ Germany } & \multicolumn{2}{|c|}{$f_{t}^{5 y 5 y}$} & \multicolumn{2}{|c|}{$s_{t}^{5 y}$} & \multicolumn{2}{|c|}{$s_{t}^{10 y}$} \\
\hline & & $0.57^{* *}$ & $(2.19)$ & $1.37^{* * *}$ & $(5.69)$ & $0.97 * * *$ & $(4.25)$ \\
\hline & Spain & $0.39^{*}$ & $(1.85)$ & $0.43^{*}$ & (1.78) & $0.41^{* *}$ & $(2.03)$ \\
\hline & Italy & -0.03 & $(-0.17)$ & 0.27 & (1.37) & 0.12 & $(0.79)$ \\
\hline & Euro Area & 0.08 & $(0.32)$ & $0.87^{* * *}$ & $(3.04)$ & $0.48^{*}$ & (1.95) \\
\hline \multirow[t]{5}{*}{ HICP } & Germany & 0.10 & $(0.57)$ & 0.21 & $(1.29)$ & 0.16 & $(1.01)$ \\
\hline & Spain & 0.24 & $(1.03)$ & $-0.50^{*}$ & $(-1.75)$ & -0.14 & $(-0.91)$ \\
\hline & France & -0.09 & $(-0.62)$ & $0.59^{* * *}$ & $(3.18)$ & $0.25^{* *}$ & $(2.25)$ \\
\hline & Italy & 0.18 & $(1.02)$ & -0.15 & $(-0.82)$ & 0.02 & $(0.09)$ \\
\hline & Euro Area & 0.06 & $(0.45)$ & 0.08 & $(0.50)$ & 0.07 & $(0.57)$ \\
\hline \multicolumn{2}{|l|}{ PPI } & -0.03 & $(-0.14)$ & $-0.33^{*}$ & $(-1.67)$ & -0.18 & $(-1.10)$ \\
\hline \multicolumn{2}{|l|}{ GDP } & $0.39 * * *$ & $(2.63)$ & 0.15 & (1.06) & $0.27^{* *}$ & $(2.11)$ \\
\hline \multicolumn{2}{|l|}{ PMI } & -0.03 & $(-0.16)$ & $0.89^{* * *}$ & $(2.61)$ & $0.43^{*}$ & $(1.91)$ \\
\hline \multicolumn{2}{|c|}{ Consumer Confidence } & 0.16 & $(1.15)$ & -0.28 & $(-1.37)$ & -0.07 & $(-0.42)$ \\
\hline \multicolumn{2}{|c|}{ Industrial Confidence } & -0.13 & $(-0.64)$ & $-0.38^{*}$ & $(-1.67)$ & -0.25 & $(-1.43)$ \\
\hline \multicolumn{2}{|c|}{ Industrial production } & $0.47 * * *$ & $(2.65)$ & 0.12 & $(0.37)$ & 0.29 & $(1.53)$ \\
\hline \multicolumn{2}{|c|}{ New orders } & -0.19 & $(-0.79)$ & -0.27 & $(-1.07)$ & -0.23 & $(-1.15)$ \\
\hline \multicolumn{2}{|c|}{ Unemployment rate } & -0.29 & $(-1.22)$ & -0.03 & $(-0.13)$ & -0.16 & $(-0.79)$ \\
\hline \multicolumn{2}{|c|}{ M3 } & -0.13 & $(-0.79)$ & 0.22 & $(1.31)$ & 0.05 & $(0.33)$ \\
\hline \multicolumn{2}{|c|}{ Retail sales } & 0.13 & $(0.80)$ & -0.04 & $(-0.25)$ & 0.04 & $(0.30)$ \\
\hline \multicolumn{2}{|c|}{ Trade balance } & -0.02 & $(-0.12)$ & -0.31 & $(-1.60)$ & -0.17 & $(-1.06)$ \\
\hline \multicolumn{2}{|c|}{ Observations } & \multicolumn{2}{|c|}{1690} & \multicolumn{2}{|c|}{1690} & \multicolumn{2}{|c|}{1690} \\
\hline \multicolumn{2}{|c|}{$R^{2}$} & \multicolumn{2}{|c|}{0.02} & \multicolumn{2}{|c|}{0.07} & \multicolumn{2}{|c|}{0.05} \\
\hline \multicolumn{2}{|c|}{$H_{0}: \beta=0 \mathrm{p}$-value } & \multicolumn{2}{|c|}{$<10^{-10}$} & \multicolumn{2}{|c|}{$<10^{-10}$} & \multicolumn{2}{|c|}{$<10^{-10}$} \\
\hline
\end{tabular}

Notes: The table reports estimated $\beta$ coefficients from regressions on days with data releases from $01: 2005$ to 03:2017. The change in various inflation compensation measures $\Delta y_{t}$ are in basis points $\left(y_{t}=f_{t}^{5 y 5 y}\right.$ denotes forward rate and $y_{t}=s_{t}^{5 y}$ and $y_{t}=s_{t}^{10 y}$ spot rates); the surprise component of macroeconomic releases $\mathbf{X}_{t}$ is normalized by their historical standard deviations; coefficients represent a basis point per standard deviation response. Heteroskedasticity-consistent t-statistics in parentheses; white standard errors are used and ***, **, and $*$ denote a 1,5 , and $10 \%$ level of significance, respectively. $H_{0}: \beta=0$ p-value is for the test that all elements of $\beta$ are zero. 
Table 3: Daily regression: coefficient estimates $\beta$ from linear regression (individual releases)

$\Delta y_{t}=\alpha+\beta x_{k t}+\varepsilon_{t}$

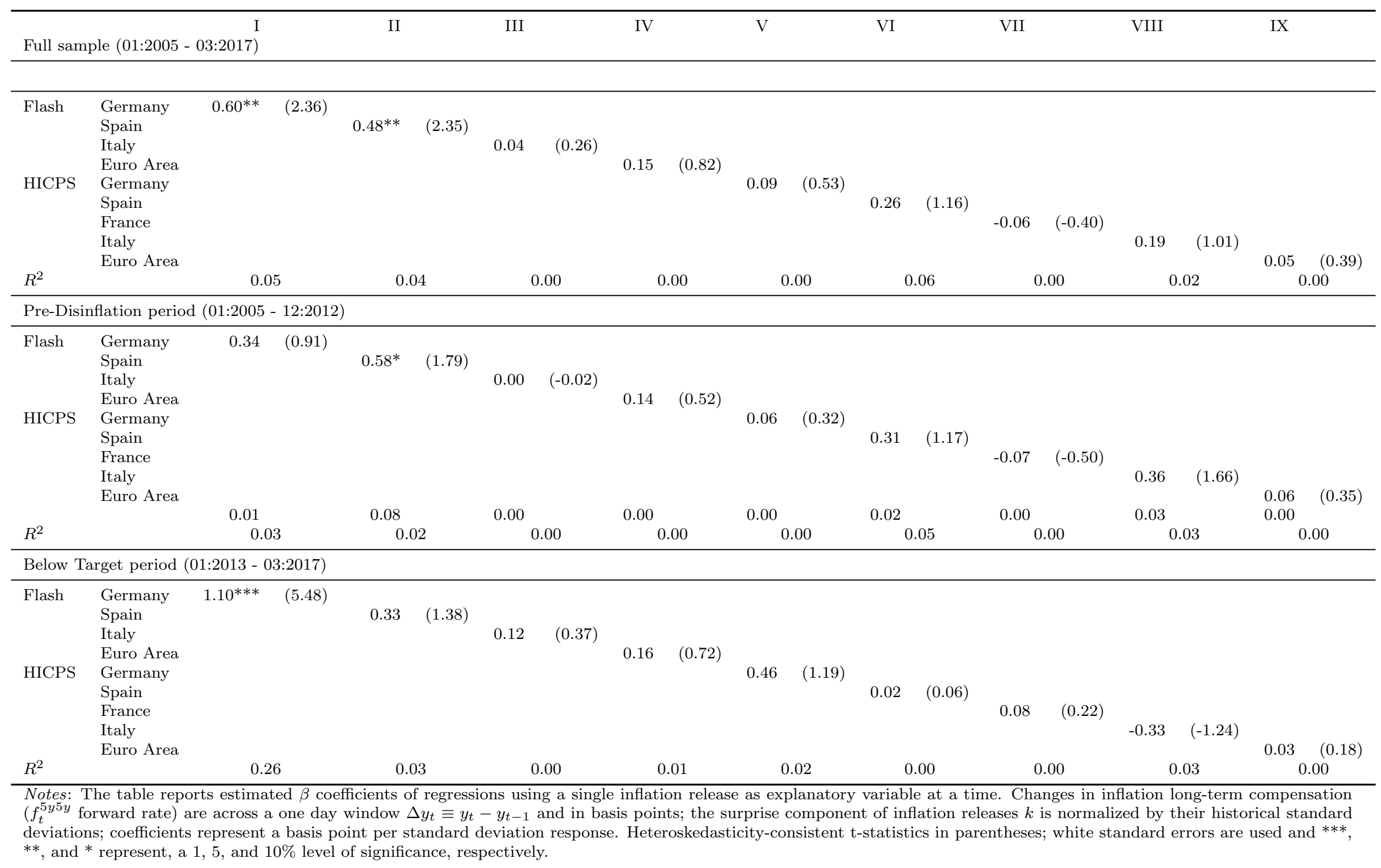


Figure 3: Time-Varying Sensitivity Coefficients $\delta^{\tau}$ from nonlinear regression

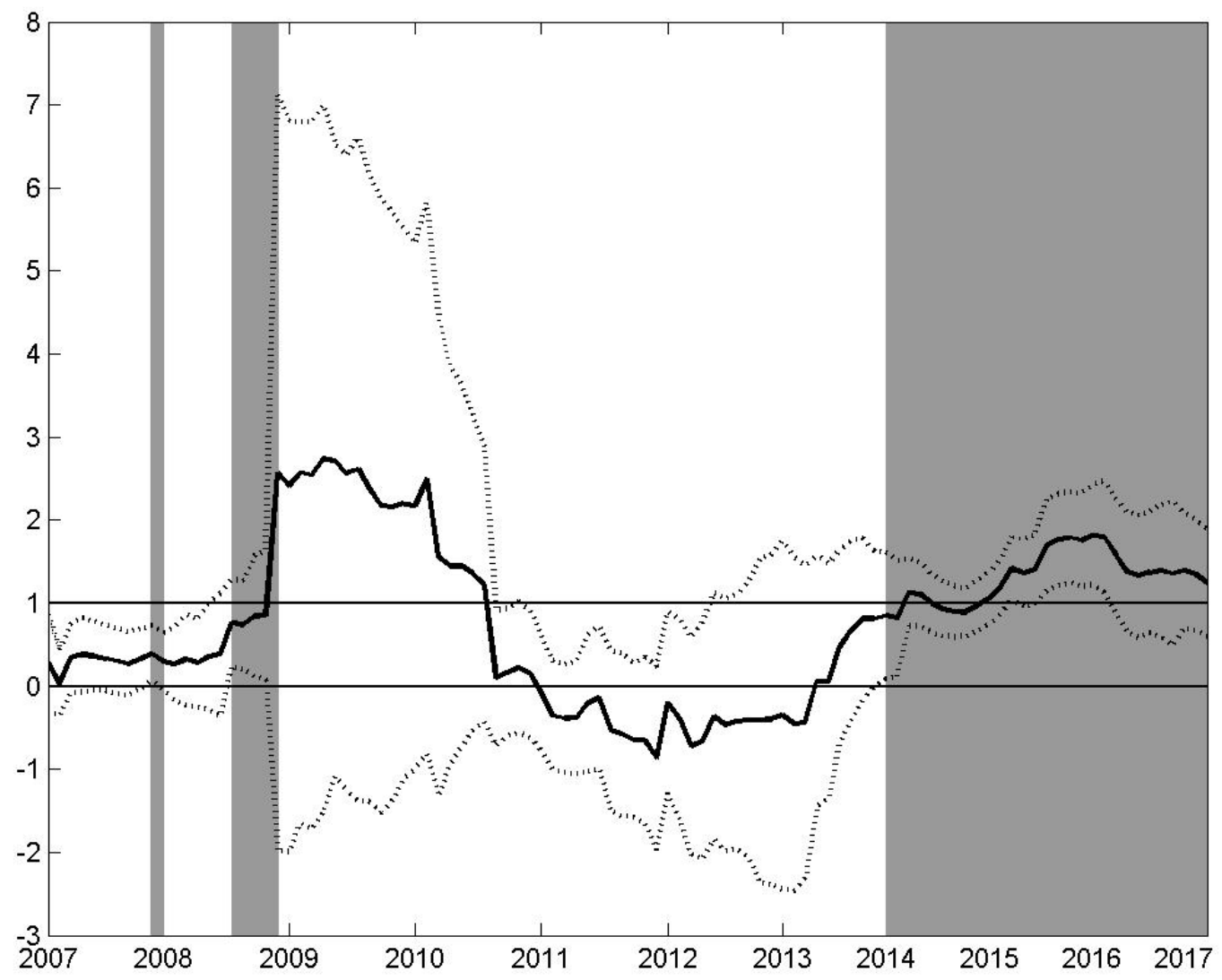

Notes: The figure plots the coefficients $\delta^{\tau}$ estimated from a regression $\Delta y_{t}=\gamma^{\tau}+\delta^{\tau} \hat{\mathbf{X}}_{t}+\epsilon_{t}^{\tau}$ at time $\tau$ using a one-sided two-year rolling window. $\delta^{\tau_{i}}$ has been normalized to an average value of 1 for the years $i=2013, \ldots, 2017$. Dotted gray lines depict heteroskedasticity-consistent \pm 2 -standard-error bands, adjusted for two-stage sampling uncertainty in $\delta^{\tau}$. White regions denote $\delta^{\tau}$ being not significant from zero and suggest inflation expectations being anchored; shaded regions denote $\delta^{\tau}$ being significantly above 0 and indicate a weaker anchoring of inflation expectations. 
Table 4: Intraday regression: coefficient estimates $\beta$ from linear regression (individual releases)

$$
\Delta y_{t}=\alpha+\beta x_{k t}+\varepsilon_{t}
$$

\begin{tabular}{|c|c|c|c|c|c|c|c|c|c|c|}
\hline & & I & II & III & IV & $\mathrm{V}$ & VI & VII & VIII & IX \\
\hline \multicolumn{11}{|c|}{ Below Target period (01:2013-03:2017) } \\
\hline \multicolumn{11}{|c|}{15 minutes window } \\
\hline Flash & Germany & $0.17^{*}(1.76)$ & & & & & & & & \\
\hline & Spain & & $0.10(1.19)$ & & & & & & & \\
\hline & Italy & & & $0.02(0.26)$ & & & & & & \\
\hline & Euro Area & & & & $0.15 *(1.78)$ & & & & & \\
\hline HICP & Germany & & & & & $-0.08(-1.02)$ & & & & \\
\hline & Spain & & & & & & $0.00(0.08)$ & & & \\
\hline & France & & & & & & & $0.07(0.87)$ & & \\
\hline & Italy & & & & & & & & $0.04(0.51)$ & \\
\hline & Euro Area & & & & & & & & & $0.01 \quad(0.09)$ \\
\hline$R^{2}$ & & 0.23 & 0.11 & 0.05 & 0.03 & 0.00 & 0.01 & 0.00 & 0.01 & 0.00 \\
\hline \multicolumn{11}{|c|}{120 minutes window } \\
\hline \multirow[t]{4}{*}{ Flash } & Germany & $0.59^{* * *}(3.74)$ & & & & & & & & \\
\hline & Spain & & $0.43^{* * *}(2.86)$ & & & & & & & \\
\hline & Italy & & & $0.11(0.43)$ & & & & & & \\
\hline & Euro Area & & & & $0.00(0.00)$ & & & & & \\
\hline \multirow[t]{5}{*}{$\mathrm{HICP}$} & Germany & & & & & $0.16(0.40)$ & & & & \\
\hline & Spain & & & & & & $0.27^{* *}(2.43)$ & & & \\
\hline & France & & & & & & & $0.26(1.18)$ & & \\
\hline & Italy & & & & & & & & 0.03 & \\
\hline & Euro Area & & & & & & & & & $-0.02(-0.16)$ \\
\hline$R^{2}$ & & 0.56 & 0.24 & 0.00 & 0.02 & 0.00 & 0.02 & 0.00 & 0.00 & 0.00 \\
\hline
\end{tabular}


Appendix 
Table A.5: Coefficient Estimates $\beta$ from Nonlinear Regression

\begin{tabular}{|c|c|c|c|c|c|c|c|}
\hline \multicolumn{8}{|c|}{$\Delta y_{t}=\gamma^{\tau_{i}}+\delta^{\tau_{i}} \beta \mathbf{X}_{t}+\epsilon_{t}$} \\
\hline & & \multicolumn{2}{|c|}{$5 y 5 y$} & \multicolumn{2}{|c|}{$5 y$} & \multicolumn{2}{|c|}{$10 y$} \\
\hline \multirow[t]{4}{*}{ Flash } & Germany & $0.71^{* * *}$ & $(3.70)$ & $1.57 * * *$ & $(4.75)$ & $1.27^{* * *}$ & $(5.37)$ \\
\hline & Spain & 0.13 & $(0.96)$ & 0.38 & $(1.64)$ & 0.22 & $(1.04)$ \\
\hline & Italy & -0.14 & $(-0.99)$ & 0.26 & $(1.41)$ & -0.05 & $(-0.32)$ \\
\hline & Euro Area & -0.13 & $(-0.65)$ & $0.76^{* *}$ & $(2.12)$ & 0.17 & $(0.59)$ \\
\hline \multirow[t]{2}{*}{$\mathrm{HICP}$} & Spain & $0.49^{*}$ & $(1.67)$ & $0.62^{* *}$ & $(2.16)$ & 0.17 & $(1.09)$ \\
\hline & Italy & 0.15 & $(0.75)$ & $0.45^{* *}$ & $(2.44)$ & $0.55^{* *}$ & $(2.18)$ \\
\hline \multicolumn{2}{|c|}{ Observations } & \multicolumn{2}{|c|}{631} & \multicolumn{2}{|c|}{631} & \multicolumn{2}{|c|}{631} \\
\hline \multicolumn{2}{|l|}{$R^{2}$} & \multicolumn{2}{|c|}{0.05} & \multicolumn{2}{|c|}{0.09} & \multicolumn{2}{|c|}{0.08} \\
\hline \multicolumn{2}{|c|}{$H_{0}: \beta$ constant, $p$-value } & \multicolumn{2}{|c|}{0.974} & \multicolumn{2}{|c|}{0.999} & \multicolumn{2}{|c|}{0.998} \\
\hline \multicolumn{2}{|c|}{$H_{0}: \delta$ symmetric, $p$-value } & \multicolumn{2}{|c|}{0.921} & \multicolumn{2}{|c|}{0.608} & \multicolumn{2}{|c|}{0.228} \\
\hline \multicolumn{2}{|c|}{$H_{0}: \delta$ constant, $p$-value } & \multicolumn{2}{|c|}{$<10^{-10}$} & \multicolumn{2}{|c|}{$<10^{-5}$} & \multicolumn{2}{|c|}{$<10^{-10}$} \\
\hline
\end{tabular}

Notes: The table reports estimated $\beta$ coefficients from regression $\Delta y_{t}=\gamma^{\tau_{i}}+\delta^{\tau_{i}} \beta \mathbf{X}_{t}+\epsilon_{t}$ on days of releases from January 2005 to March 2017. Coefficients indexed $\tau_{i}$ may take on different values in different calendar years. Heteroskedasticity-consistent t-statistics in parentheses; white standard errors are used and $* * *, * *$, and $*$ represent a 1,5 , and $10 \%$ level of significance, respectively. $H_{0}: \beta$ constant implies that each coefficient of $\beta$ in regression (4) is constant over time and only the scalar coefficients $\delta^{\tau_{i}}$ vary against an alternative in which every element of $\beta$ is permitted to vary independently across calendar years. $H_{0}: \delta$ symmetric assumes that the $\delta^{\tau_{i}}$ in (4) are the same for positive and negative surprises $\beta \mathbf{X}_{t}$, against an alternative in which we allow separate coefficients $\delta_{+}^{\tau_{i}}$ and $\delta_{-}^{\tau_{i}}$ for positive and negative values of $\beta \mathbf{X}_{t}$ in each calendar year $i . H_{0}: \delta$ constant assumes that the time-varying sensitivity coefficients $\delta^{\tau_{i}}$ in (4) are constant over time. That is, we test whether $\delta^{\tau_{i}}=1$ for each calendar year $i=2005, \ldots, 2015$. 
Figure A.4: Time-Varying Sensitivity Coefficients $\delta^{\tau}$ from nonlinear regression (Alternative normalization periods)

(a) $\delta^{\tau_{i}}$ normalized across $2005-2008$

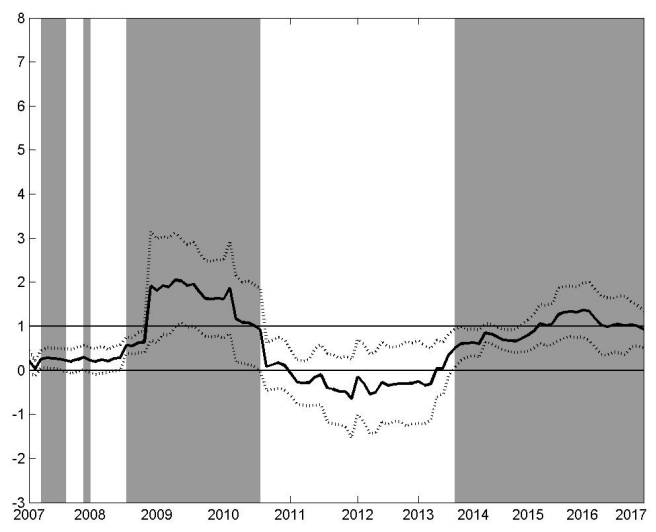

(b) $\delta^{\tau_{i}}$ normalized across $2008-2012$

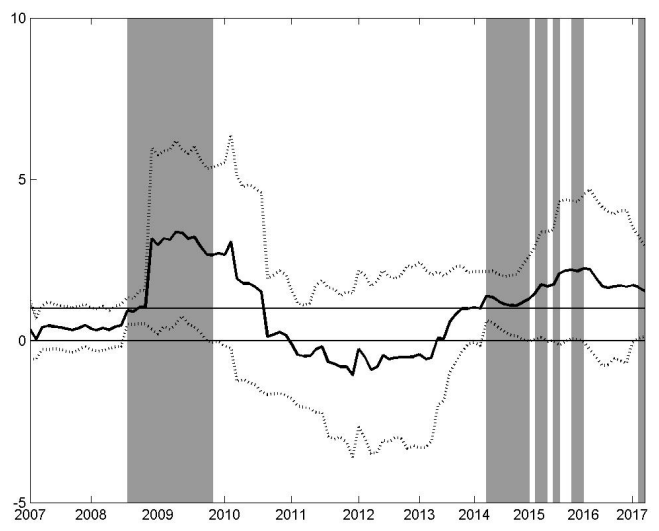

(c) $\delta^{\tau_{i}}$ normalized across $2005-2011$

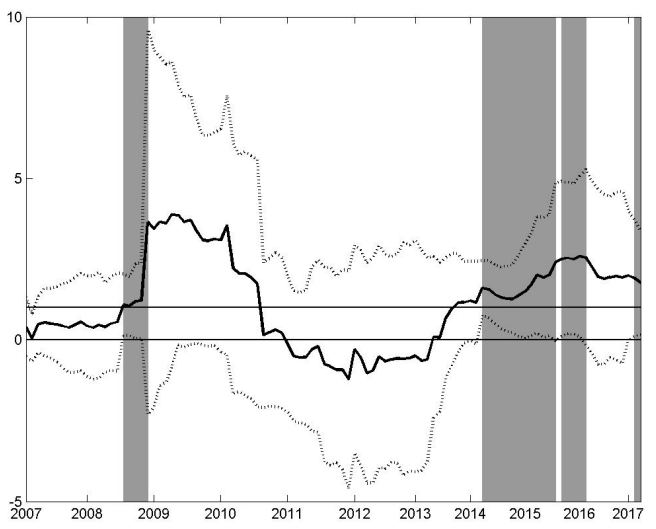

Notes: The figure plots the coefficients $\delta^{\tau}$ estimated from a regression $\Delta y_{t}=\gamma^{\tau}+\delta^{\tau} \hat{\mathbf{X}}_{t}+\epsilon_{t}^{\tau}$ at time $\tau$ using a one-sided two-year rolling window. $\delta^{\tau_{i}}$ has been normalized to an average value of 1 in Panel (a) for the years $i=2005, \ldots, 2008$; in Panel (b) for the years $i=2008, \ldots, 2012$ and in Panel (c) for the years $i=2005, \ldots, 2011$. Dotted gray lines depict heteroskedasticity-consistent \pm 2 -standard-error bands, adjusted for two-stage sampling uncertainty in $\delta^{\tau}$. White regions denote $\delta^{\tau}$ being not significant from zero and suggest inflation expectations being anchored; shaded regions denote $\delta^{\tau}$ being significantly above 0 and suggest a weaker anchoring of inflation expectations. 
Figure A.5: Time-Varying Sensitivity Coefficients $\delta^{\tau}$ (Alternative HICP releases)

(a) EA and German HICP

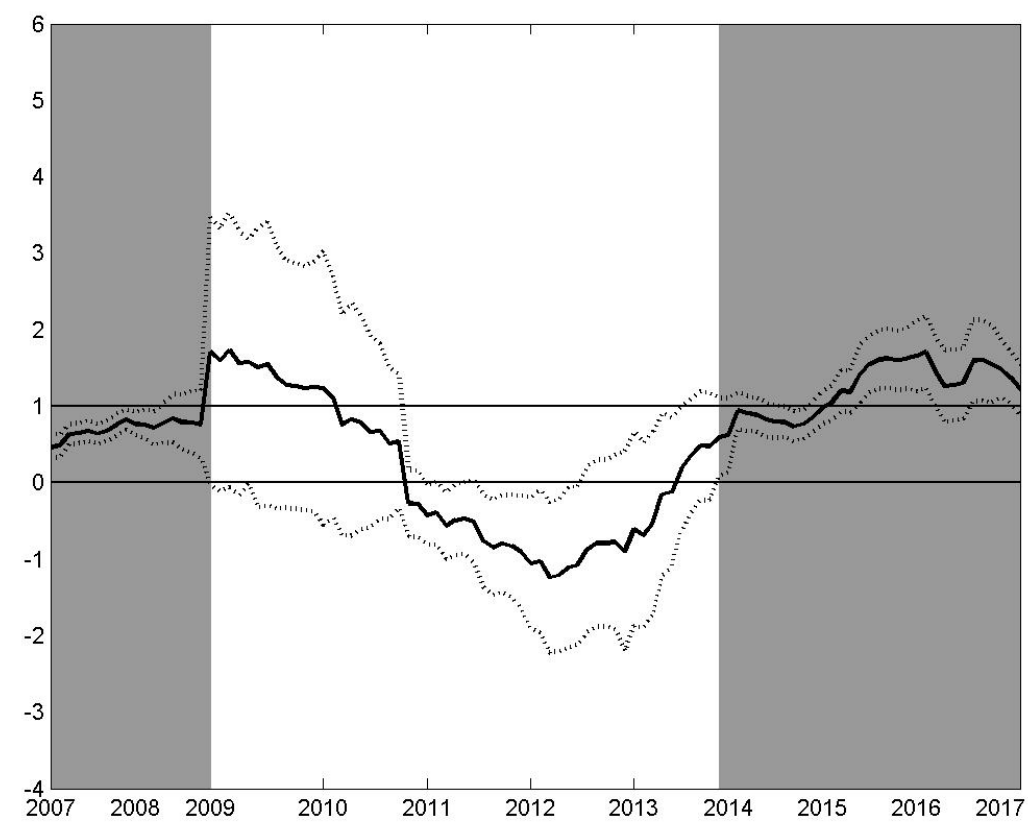

(b) EA and Spanish HICP

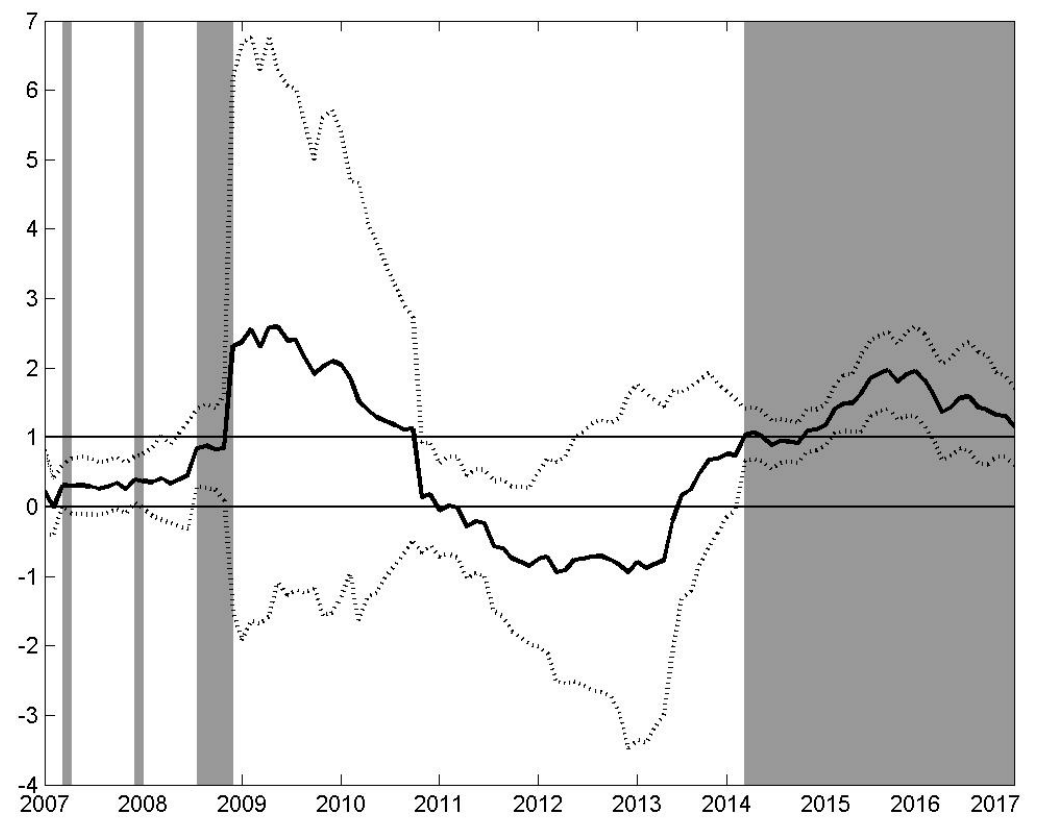

Notes: The figure plots the coefficients $\delta^{\tau}$ estimated from a regression $\Delta y_{t}=\gamma^{\tau}+\delta^{\tau} \hat{\mathbf{X}}_{t}+\epsilon_{t}^{\tau}$ at time $\tau$ using a one-sided two-year rolling window. $\delta^{\tau_{i}}$ has been normalized to an average value of 1 for the years $i=2013, \ldots, 2017$. Surprises for Spanish and Italian HICP used in our benchmark specification (Figure 3) are replaced in Panel (a) by euro area and German HICP and in Panel (b) by euro area and Spanish HICP. Dotted gray lines depict heteroskedasticity-consistent \pm 2 -standard-error bands, adjusted for two-stage sampling uncertainty in $\delta^{\tau}$. White regions denote $\delta^{\tau}$ being not significant from zero and suggest inflation expectations being anchored; shaded regions denote $\delta^{\tau}$ being significantly above 0 and suggest a weaker anchoring of inflation expectations. 
Figure A.6: Time-Varying Sensitivity Coefficients $\delta^{\tau}$ (Alternative HICP releases) (cont.)

(c) EA and French HICP

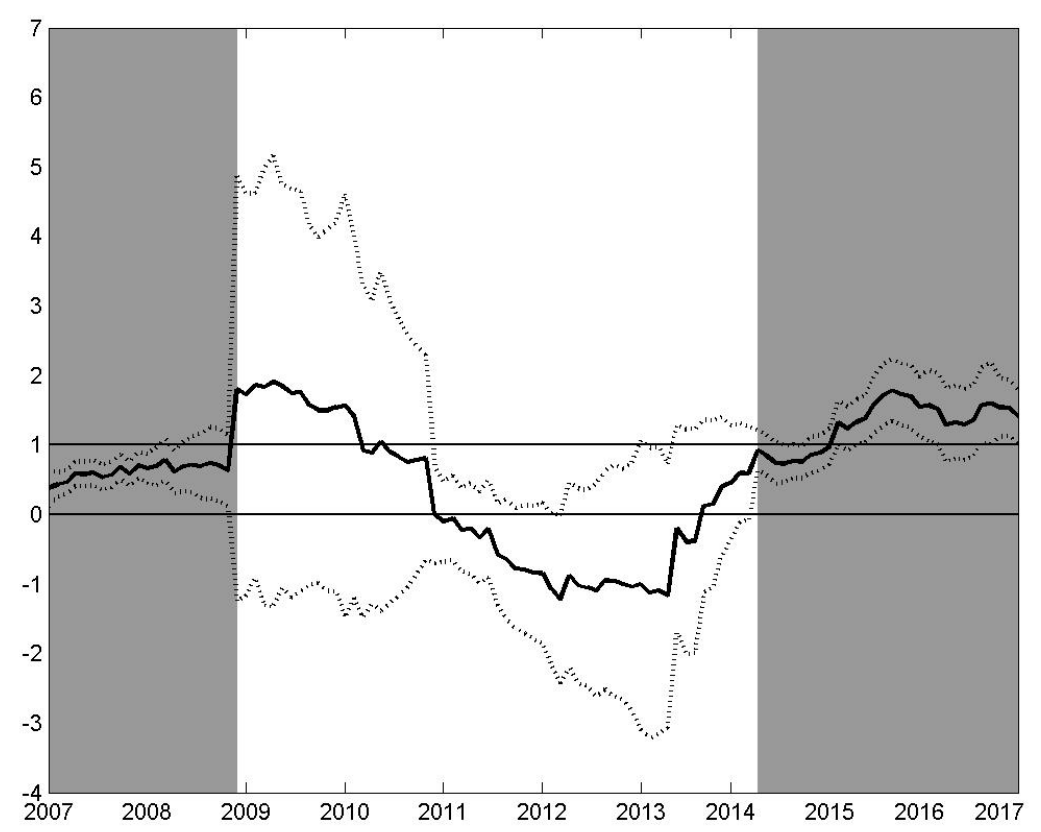

(d) EA and Italian HICP

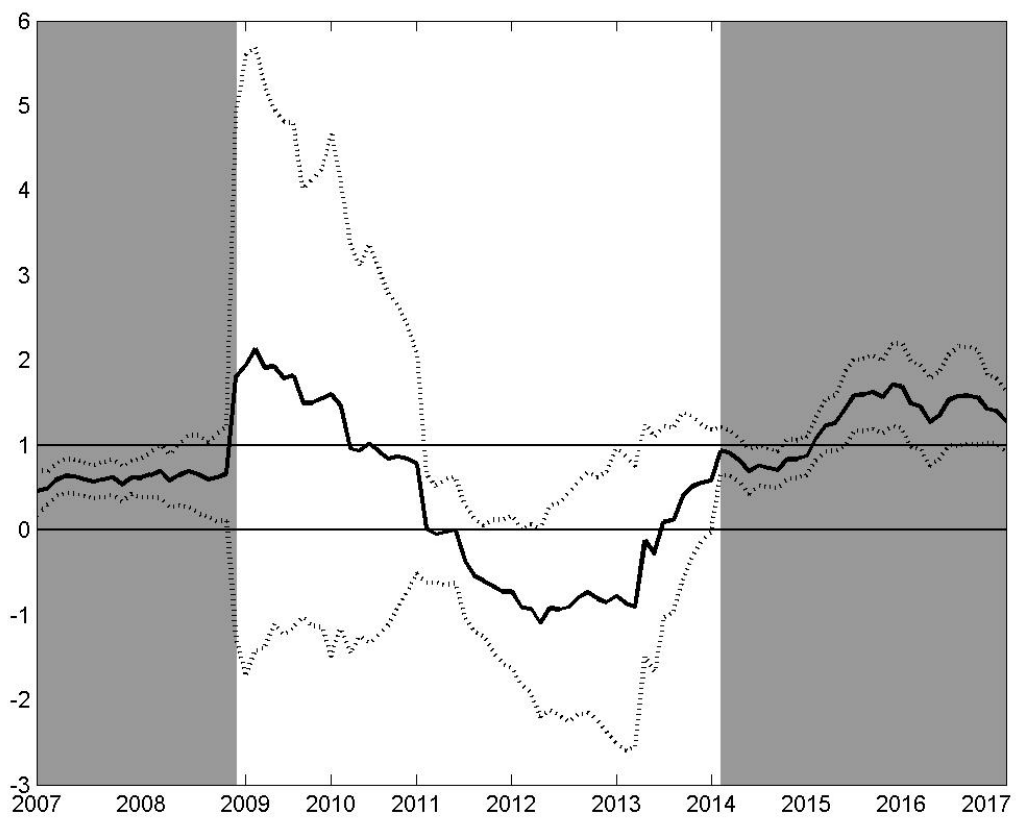

Notes: The figure plots the coefficients $\delta^{\tau}$ (using $\Delta y_{t}=\gamma^{\tau}+\delta^{\tau} \hat{\mathbf{X}}_{t}+\epsilon_{t}^{\tau}$ ) at time $\tau$ of a one-sided two-year backward looking window. Surprises for Spanish and Italian HICP used in our benchmark specification (Figure 3) are replaced in Panel (c) by euro area and French HICP and in Panel (d) by euro area and Italian HICP. Dotted gray lines depict heteroskedasticity-consistent \pm 2 -standard-error bands, adjusted for two-stage sampling uncertainty in $\delta^{\tau}$. White regions denote $\delta^{\tau}$ being not significant from zero and indicate inflation expectations being anchored; shaded regions denote $\delta^{\tau}$ being significantly above 0 and indicate a weaker anchoring of inflation expectations. 
Table A.6: Inflation news and other market indicators, Full sample (01:2005 - 03:2017)

$$
\Delta y_{t}=\alpha+\beta x_{k t}+\gamma z_{p t}+\varepsilon_{t}
$$

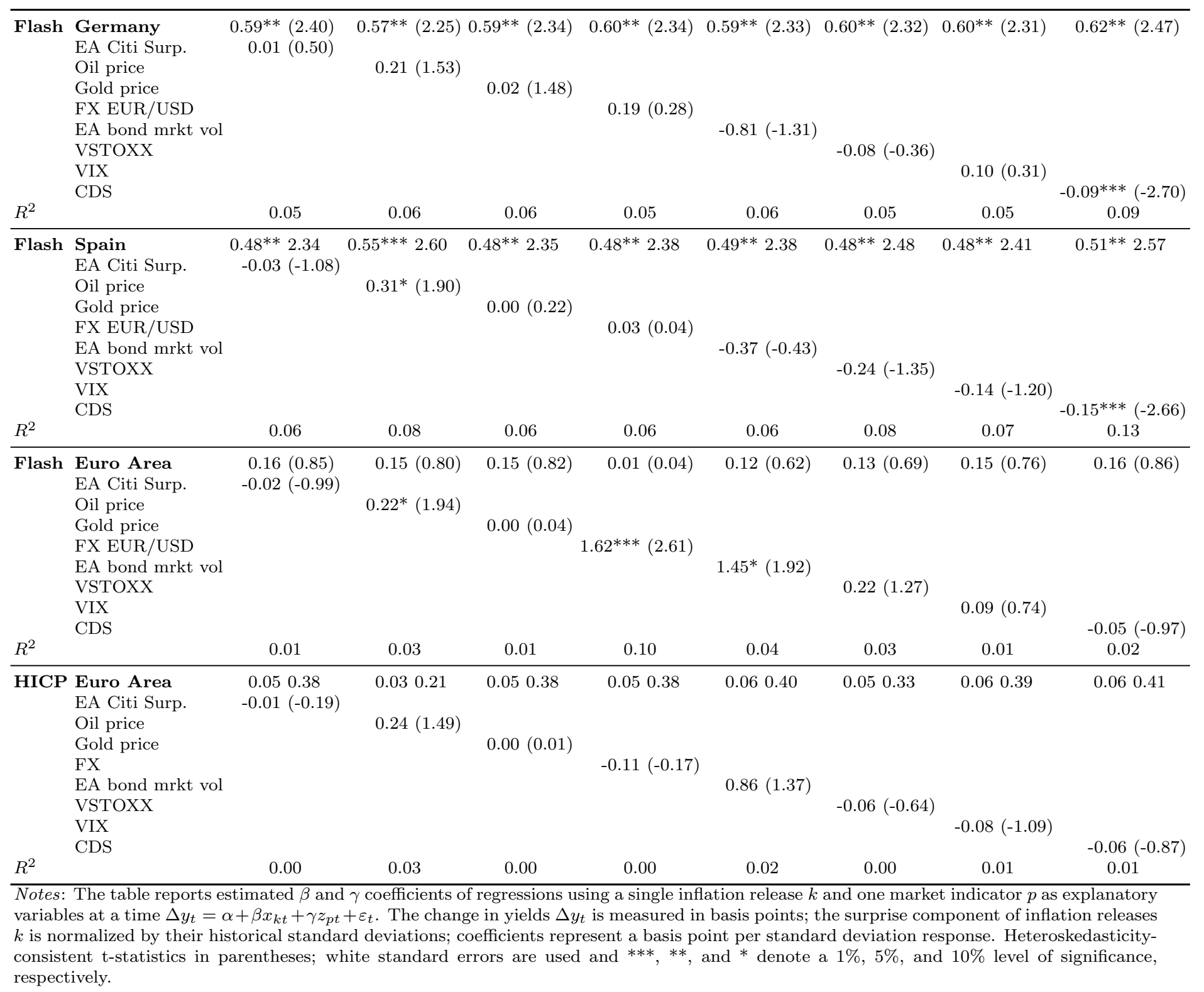


Table A.7: Inflation news and other market indicators, Pre-Disinflation period (01:2005 - 12:2012)

$$
\Delta y_{t}=\alpha+\beta x_{k t}+\gamma z_{p t}+\varepsilon_{t}
$$

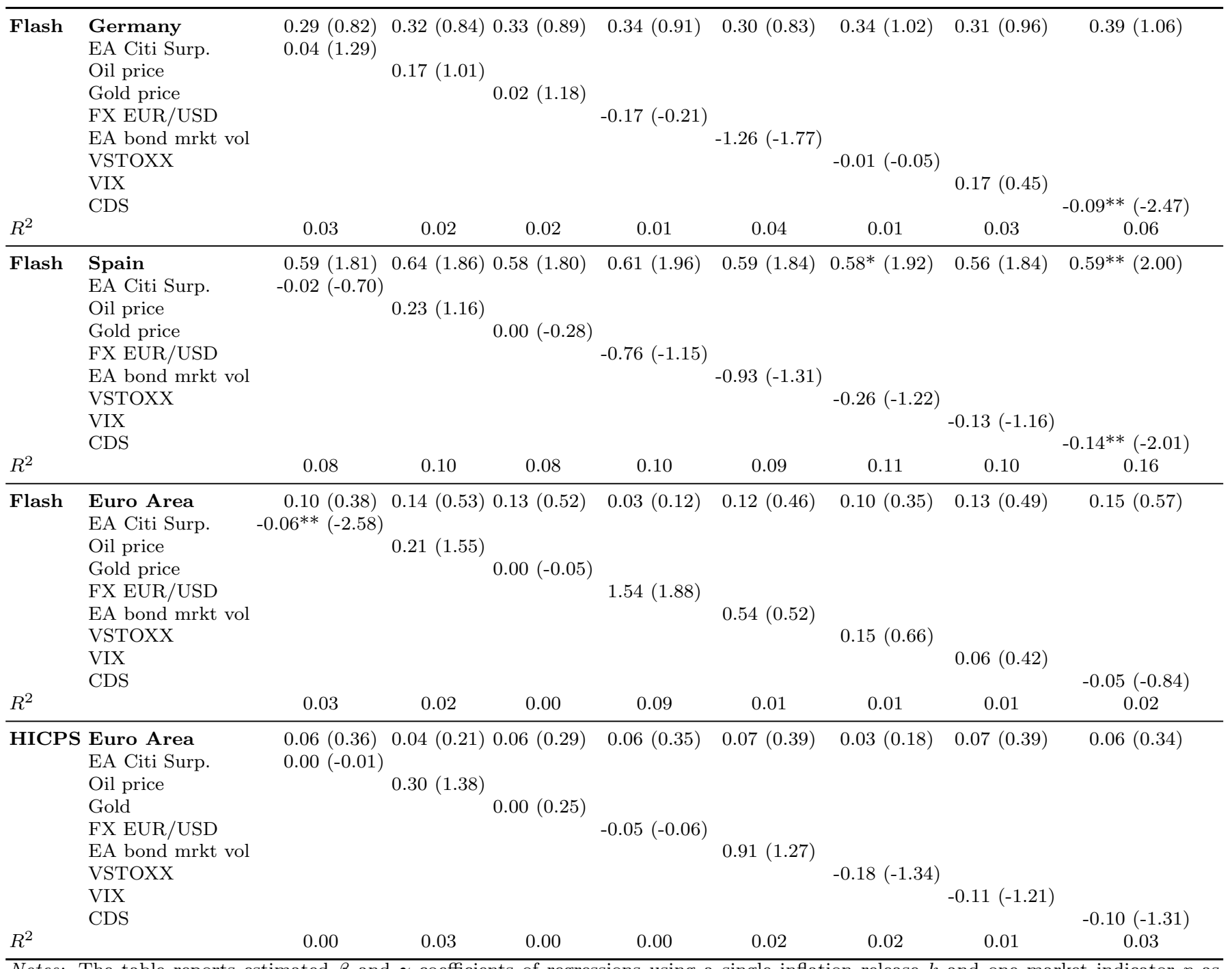

Notes: The table reports estimated $\beta$ and $\gamma$ coefficients of regressions using a single inflation release $k$ and one market indicator $p$ as explanatory variables at a time $\Delta y_{t}=\alpha+\beta x_{k t}+\gamma z_{p t}+\varepsilon_{t}$. The change in yields $\Delta y_{t}$ is measured in basis points; the surprise component of inflation releases $k$ is normalized by their historical standard deviations; coefficients represent a basis point per standard deviation response. Heteroskedasticity-consistent t-statistics in parentheses; white standard errors are used and $* * *, * *$, and $*$ denote a $1 \%, 5 \%$, and $10 \%$ level of significance, respectively. 
Table A.8: Inflation news and other market indicators, Below Target period (01:2013 - 03:2017)

$$
\Delta y_{t}=\alpha+\beta x_{k t}+\gamma z_{p t}+\varepsilon_{t}
$$

\begin{tabular}{|c|c|c|c|c|c|c|c|c|c|}
\hline Flash & $\begin{array}{l}\text { Germany } \\
\text { EA Citi Surp. } \\
\text { Oil price } \\
\text { Gold price } \\
\text { FX EUR/USD } \\
\text { EA bond mrkt vol } \\
\text { VSTOXX } \\
\text { VIX } \\
\text { CDS }\end{array}$ & $\begin{array}{l}1.17^{* * *}(5.63) \\
-0.11^{* *}(-2.39)\end{array}$ & $\begin{array}{r}1.08^{* * *}(5.33) \\
0.25(1.11)\end{array}$ & $1.08^{* * *}(5.54)$ & $1.11^{* * *}(5.34)$ & $1.10^{* * *}(5.57)$ & $\begin{array}{c}-0.27(-1.30) \\
0.29\end{array}$ & $\begin{array}{c}-0.09(-0.34) \\
0.26\end{array}$ & $\begin{array}{c}-0.12^{* *}(-2.41) \\
0.29\end{array}$ \\
\hline Flash & $\begin{array}{l}\text { Spain } \\
\text { EA Citi Surp. } \\
\text { Oil price } \\
\text { Gold price } \\
\text { FX EUR/USD } \\
\text { EA bond mrkt vol } \\
\text { VSTOXX } \\
\text { VIX } \\
\text { CDS }\end{array}$ & $\begin{array}{c}0.28(1.11) \\
-0.06(-0.87)\end{array}$ & $\begin{array}{r}0.40 *(1.77) \\
0.54(1.56)\end{array}$ & $\begin{array}{l}0.34(1.40) \\
0.01(0.41)\end{array}$ & $\begin{array}{c}0.25(0.84) \\
1.68^{*}(1.75)\end{array}$ & $0.31(0.21)$ & $-0.19(-0.60)$ & $-0.15(-0.43)$ & $\begin{array}{r}0.37(1.46) \\
-0.15^{* *}(-2.16)\end{array}$ \\
\hline$R^{2}$ & & 0.05 & 0.08 & 0.03 & 0.10 & 0.03 & 0.03 & 0.03 & 0.08 \\
\hline Flash & $\begin{array}{l}\text { Euro Area } \\
\text { EA Citi Surp. } \\
\text { Oil price } \\
\text { Gold price } \\
\text { FX EUR/USD } \\
\text { EA bond mrkt vol } \\
\text { VSTOXX } \\
\text { VIX } \\
\text { CDS }\end{array}$ & $\begin{array}{l}0.07(0.27) \\
0.04(0.74)\end{array}$ & $\begin{array}{l}0.16(0.67) \\
0.25(1.12)\end{array}$ & $\begin{array}{l}0.16(0.68) \\
0.00(0.06)\end{array}$ & $-0.18(-0.74)$ & $\begin{array}{r}0.06(0.36) \\
2.67^{* * *}(3.62)\end{array}$ & $\begin{array}{r}0.28(1.26) \\
0.53^{* * *}(2.90)\end{array}$ & 列 & $0.15(0.70)$ \\
\hline$R^{2}$ & & 0.03 & 0.04 & 0.01 & 0.17 & 0.20 & 0.12 & 0.03 & 0.02 \\
\hline HICPS & $\begin{array}{l}\text { Euro Area } \\
\text { EA Citi Surp. } \\
\text { Oil price } \\
\text { Gold price } \\
\text { FX EUR/USD } \\
\text { EA bond mrkt vol } \\
\text { VSTOXX } \\
\text { VIX } \\
\text { CDS }\end{array}$ & $\begin{array}{c}0.19(0.95) \\
-0.20^{* *}(-2.16)\end{array}$ & $\begin{array}{l}0.01(0.07) \\
0.12(0.53)\end{array}$ & $\begin{array}{c}0.01(0.07) \\
-0.01(-0.70)\end{array}$ & $\begin{array}{c}0.02(0.15) \\
-0.29(-0.40)\end{array}$ & $0.02(0.13)$ & $0.01(0.06)$ & $\begin{array}{l}0.06(0.43) \\
0.00\end{array}$ & $\begin{array}{c}0.17(1.15) \\
0.06\end{array}$ \\
\hline
\end{tabular}


Table A.9: Daily regression: coefficient estimates $\beta$ from linear regression (individual releases)

$\Delta y_{t}=\alpha+\beta x_{k t}+\varepsilon_{t}$

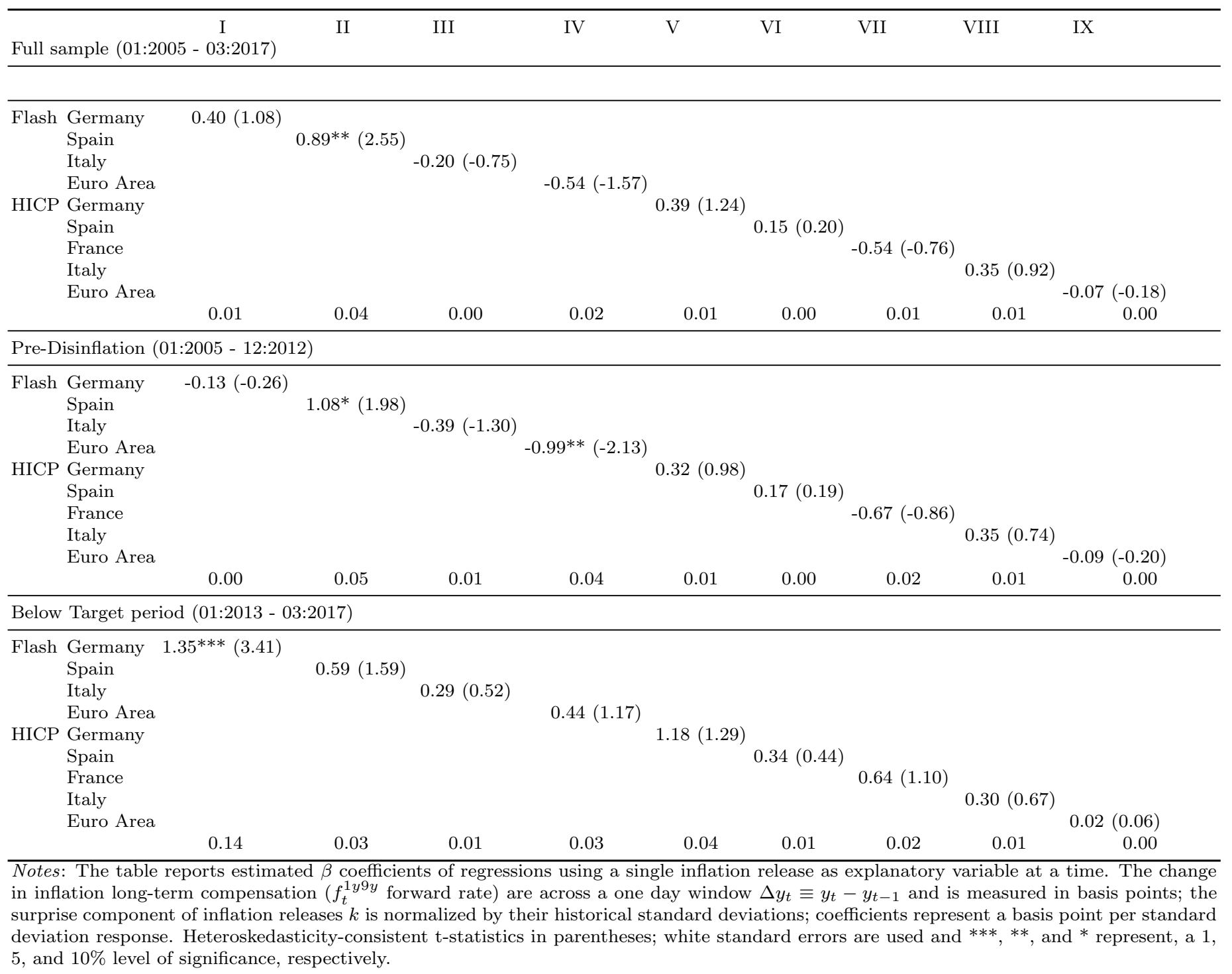


Table A.10: 2-day window regression: coefficient estimates $\beta$ from linear regression (individual releases)

$\Delta y_{t}=\alpha+\beta x_{k t}+\varepsilon_{t}$

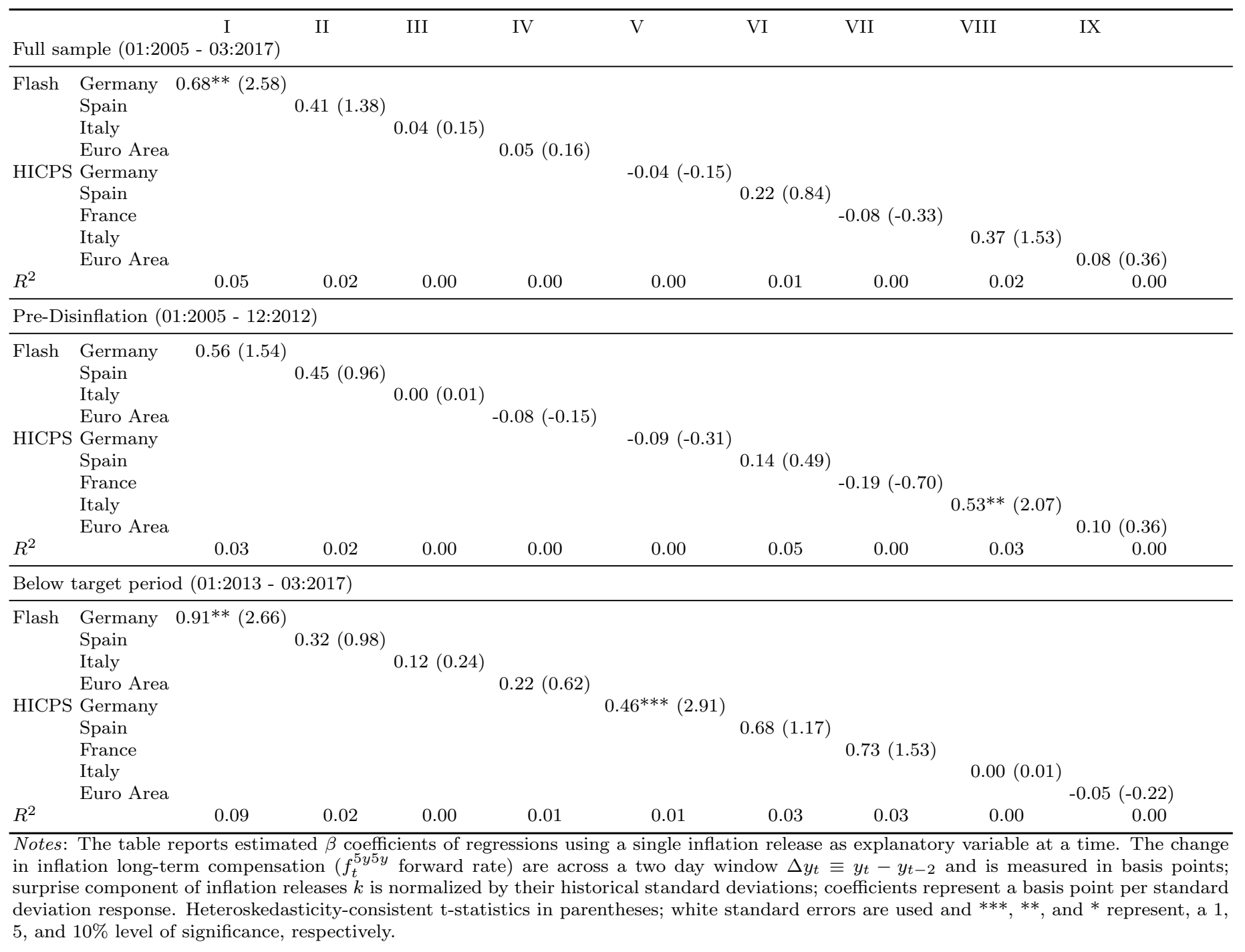


Table A.11: Sign distribution of change in inflation expectations around macroeconomic releases

\begin{tabular}{|c|c|c|c|c|c|c|c|c|c|c|c|c|c|}
\hline & & \multicolumn{3}{|c|}{$\begin{array}{c}\text { Full } \\
(01: 2005-12: 2012)\end{array}$} & \multicolumn{3}{|c|}{$\begin{array}{l}\text { Pre-Disinflation } \\
(01: 2005-03: 2017)\end{array}$} & \multicolumn{3}{|c|}{$\begin{array}{l}\text { Pre-Disinflation } \\
\text { (Excl. Lehman) }\end{array}$} & \multicolumn{3}{|c|}{$\begin{array}{c}\text { Below Target } \\
(01: 2013-03: 2017)\end{array}$} \\
\hline & & Plus & Zero & Minus & Plus & Zero & Minus & Plus & Zero & Minus & Plus & Zero & Minus \\
\hline \multirow[t]{4}{*}{ Flash } & Germany & 61 & 24 & 56 & 33 & 23 & 35 & 29 & 22 & 30 & 28 & 1 & 21 \\
\hline & Spain & 71 & 20 & 48 & 45 & 20 & 26 & 41 & 19 & 21 & 26 & 0 & 22 \\
\hline & Italy & 84 & 18 & 41 & 56 & 15 & 23 & 50 & 15 & 19 & 28 & 3 & 18 \\
\hline & Euro Area & 86 & 16 & 43 & 58 & 14 & 24 & 53 & 14 & 19 & 28 & 2 & 19 \\
\hline \multirow[t]{17}{*}{ HICP } & Germany & 63 & 6 & 67 & 41 & 6 & 40 & 36 & 6 & 35 & 22 & 0 & 27 \\
\hline & Spain & 56 & 10 & 74 & 35 & 10 & 46 & 30 & 10 & 42 & 21 & 0 & 28 \\
\hline & France & 64 & 15 & 67 & 44 & 15 & 38 & 41 & 14 & 33 & 20 & 0 & 29 \\
\hline & Italy & 53 & 10 & 70 & 35 & 10 & 43 & 30 & 9 & 39 & 18 & 0 & 27 \\
\hline & Euro Area & 63 & 16 & 67 & 41 & 14 & 41 & 36 & 14 & 36 & 22 & 2 & 26 \\
\hline & PPI & 64 & 16 & 66 & 41 & 14 & 41 & 35 & 14 & 38 & 23 & 2 & 25 \\
\hline & GDP & 49 & 14 & 63 & 36 & 14 & 38 & 33 & 14 & 32 & 13 & 0 & 25 \\
\hline & PMI & 102 & 7 & 99 & 63 & 4 & 66 & 58 & 4 & 52 & 39 & 3 & 33 \\
\hline & Consumer confidence & 102 & 15 & 80 & 70 & 14 & 45 & 64 & 13 & 42 & 32 & 1 & 35 \\
\hline & Industrial confidence & 79 & 13 & 52 & 55 & 12 & 28 & 49 & 11 & 25 & 24 & 1 & 24 \\
\hline & Industrial production & 64 & 15 & 67 & 41 & 14 & 41 & 36 & 14 & 37 & 23 & 1 & 26 \\
\hline & New orders & 37 & 11 & 38 & 37 & 11 & 38 & 33 & 11 & 32 & & & \\
\hline & Unemployment rate & 91 & 5 & 50 & 57 & 4 & 35 & 53 & 4 & 30 & 34 & 1 & 15 \\
\hline & M3 & 66 & 21 & 59 & 41 & 19 & 35 & 34 & 18 & 33 & 25 & 2 & 24 \\
\hline & Retail sales & 62 & 11 & 74 & 39 & 9 & 48 & 33 & 9 & 45 & 12 & 0 & 11 \\
\hline & Trade balance & 57 & 7 & 62 & 36 & 7 & 39 & 31 & 7 & 34 & 21 & 0 & 23 \\
\hline & No News & 769 & 169 & 752 & 515 & 154 & 485 & 459 & 150 & 424 & 245 & 13 & 258 \\
\hline
\end{tabular}

Notes: The table reports the sign distribution of changes in EA inflation long-term compensation ( $f_{t}^{5 y 5 y}$ forward rate) on days of data releases. The last row reports the asign distribution on days no relevant data is released. Pre-Disinflation (Excl. Lehman) excludes the 9 months (2008:10-2009:06) after the collapse of Lehman Brothers, due to the exessive market volatility, including for inflation compensation measure over these months. 
Figure A.7: Distribution of Macroeconomic Surprises: Flash Germany and Spain

Flash Germany

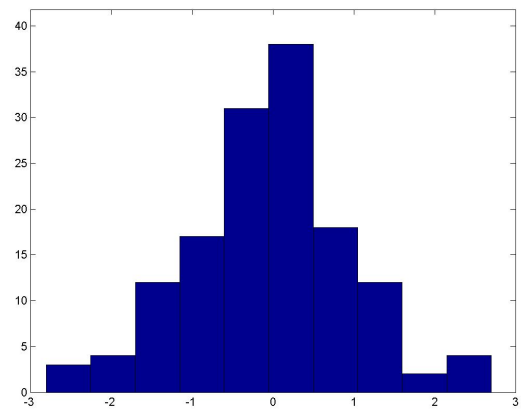

Flash Spain

Full

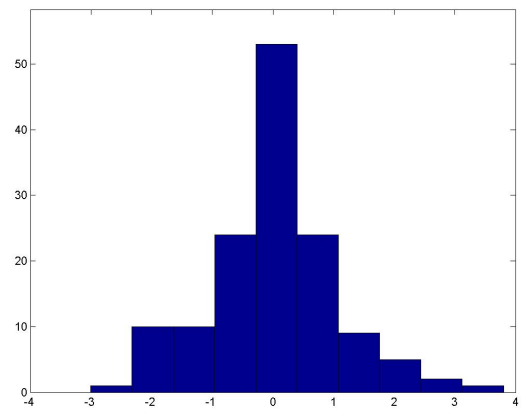

Pre-Disinflation
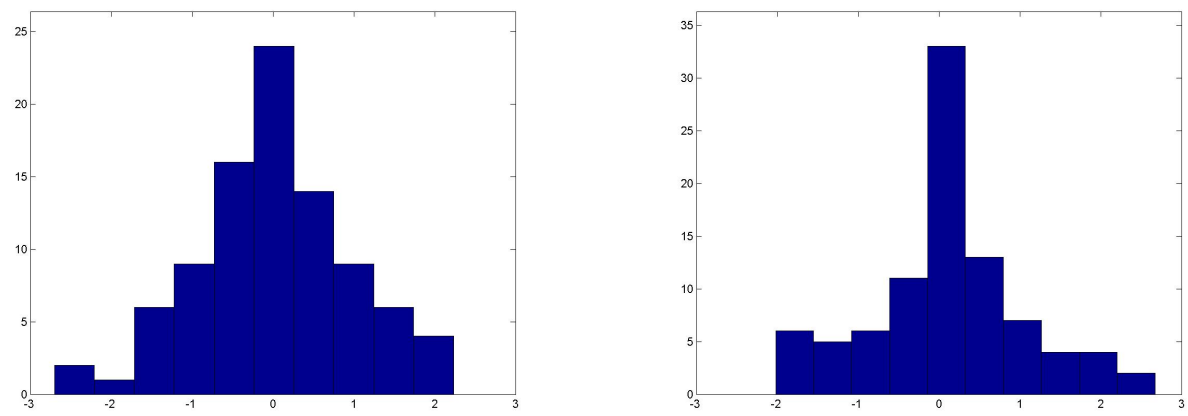

Pre-Disinflation

(Excluding 9 months period after Lehman Brothers collapse)
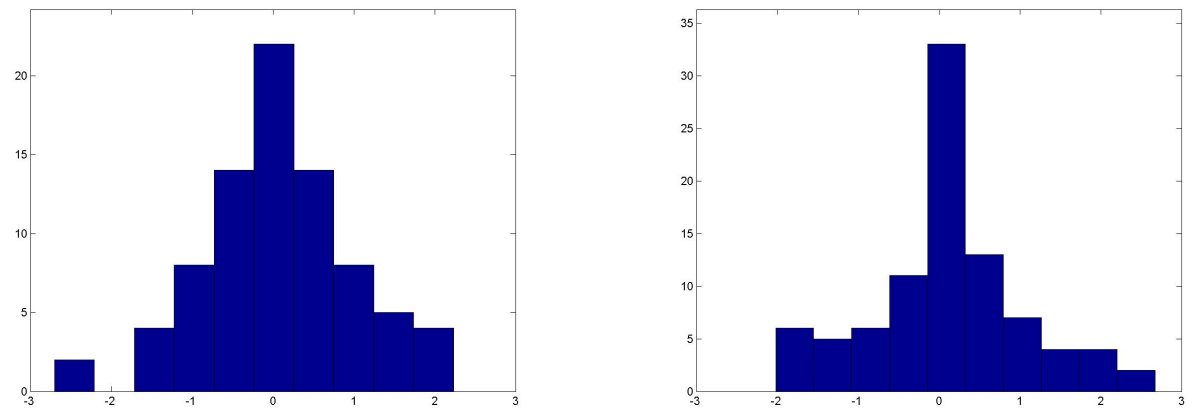

Below Target
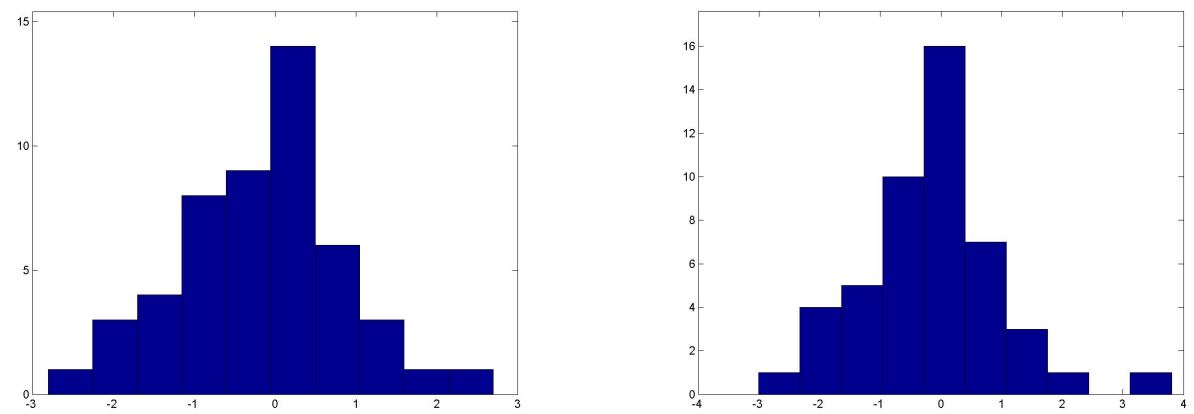
Figure A.8: Distribution of Macroeconomic Surprises: Flash Italy and Euro Area

Flash Italy

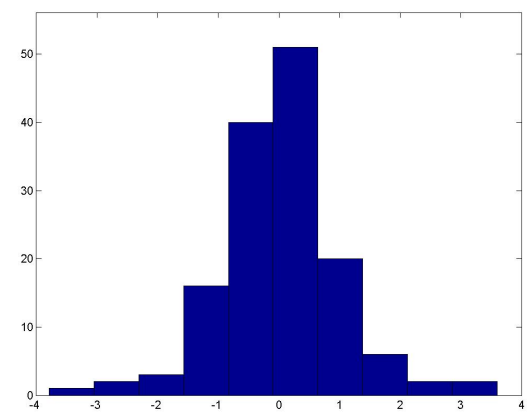

Flash Euro Area

Full

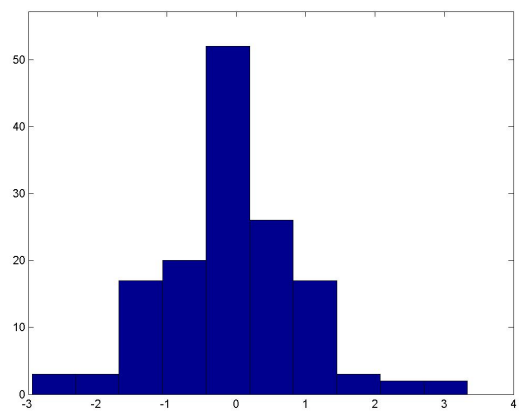

Pre-Disinflation
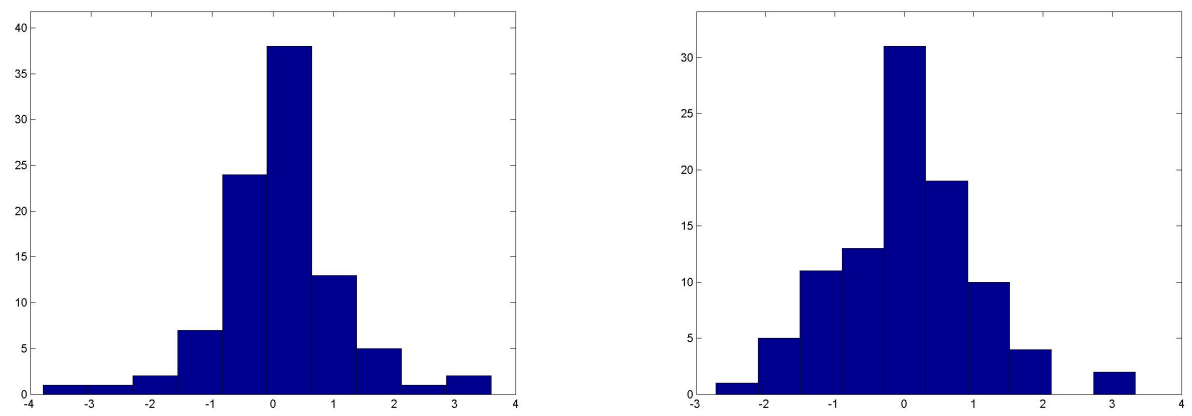

Pre-Disinflation

(Excluding 9 months period after Lehman Brothers collapse)
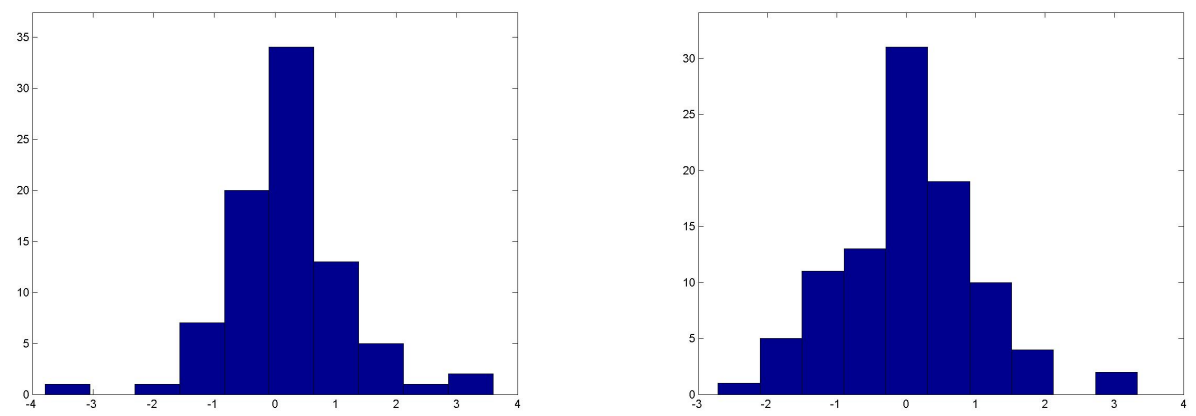

Below Target
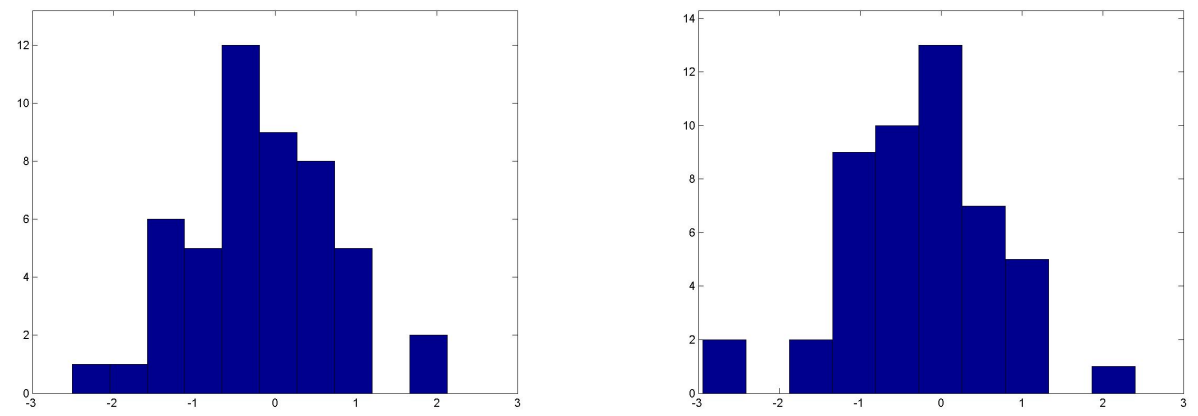
Figure A.9: Distribution of Macroeconomic Surprises: HICP Germany and Spain

HICP Germany

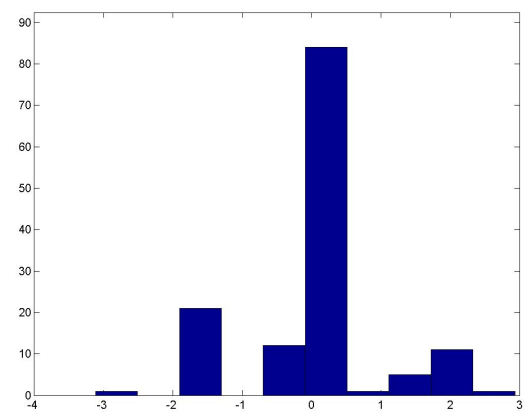

HICP Spain

Full

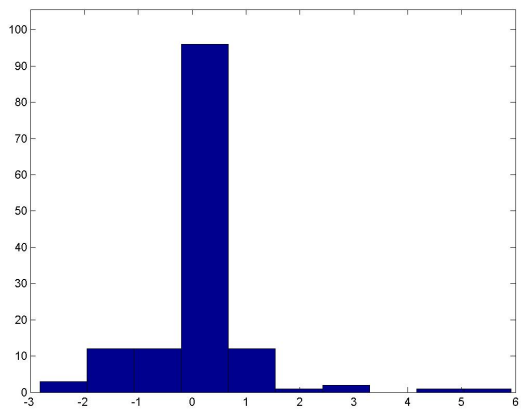

Pre-Disinflation
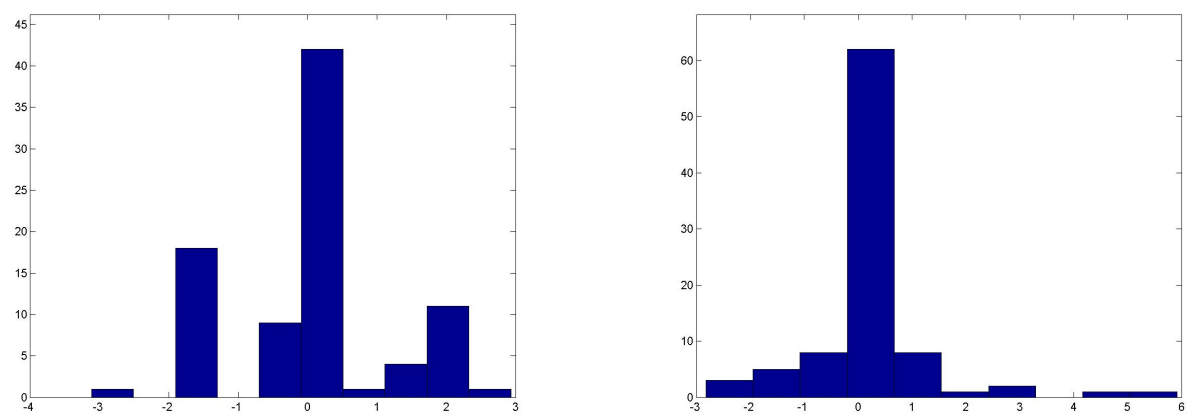

Pre-Disinflation

(Excluding 9 months period after Lehman Brothers collapse)
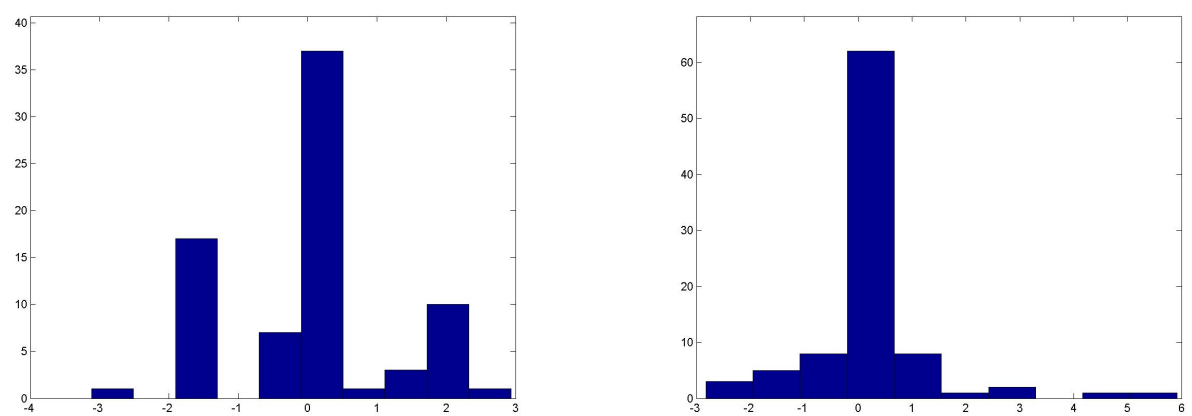

Below Target
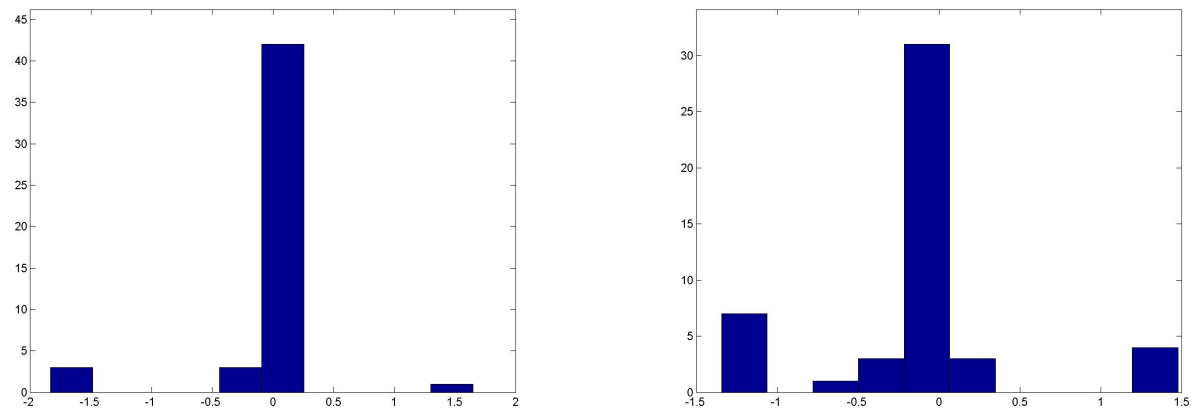
Figure A.10: Distribution of Macroeconomic Surprises: HICP France and Italy

HICP France

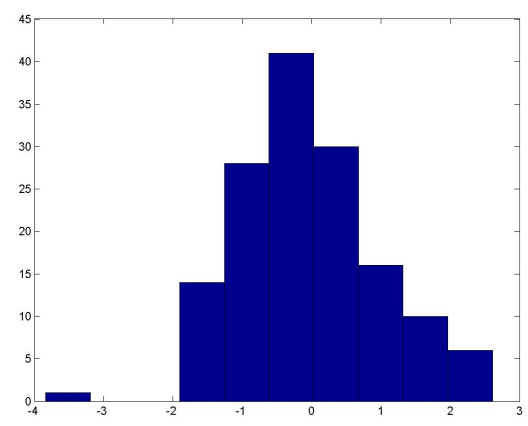

HICP Italy

Full

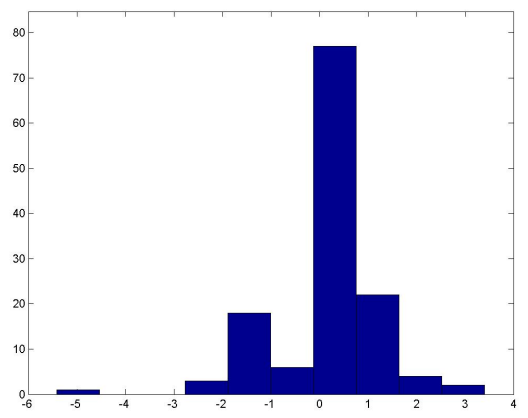

Pre-Disinflation
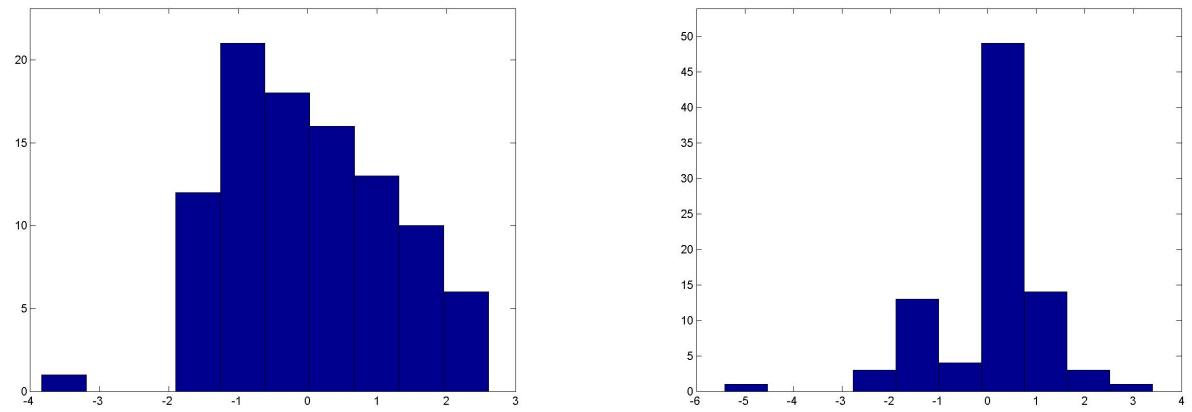

Pre-Disinflation

(Excluding 9 months period after Lehman Brothers collapse)
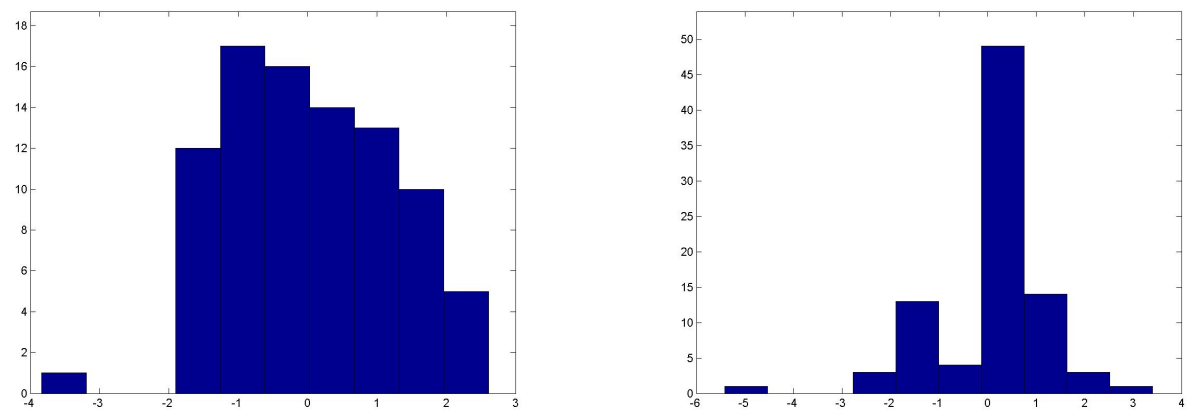

Below Target
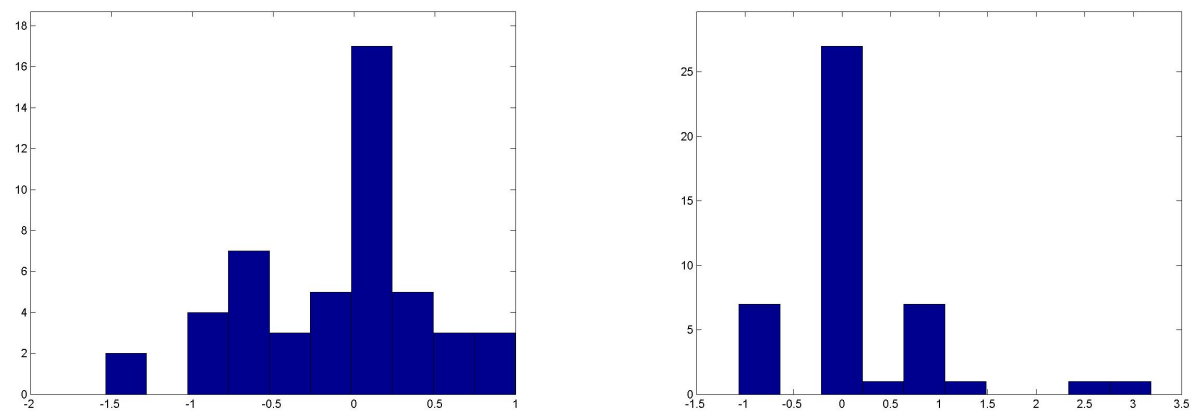
Figure A.11: Distribution of Macroeconomic Surprises: HICP euro area

HICP euro area

Full

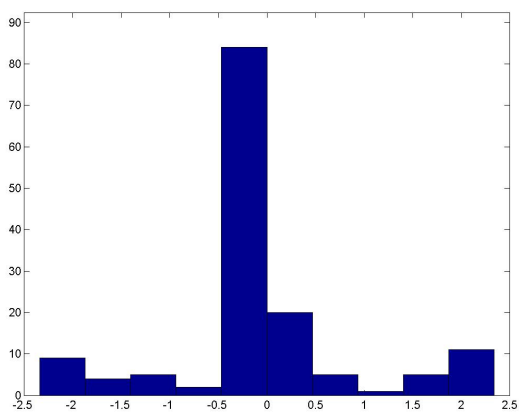

Pre-Disinflation

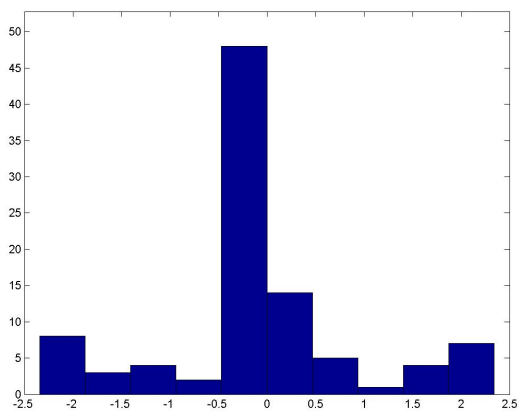

Pre-Disinflation

(Excluding 9 months period after Lehman Brothers collapse)

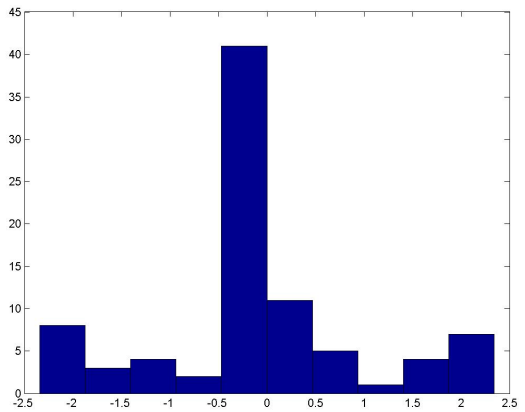

Below Target

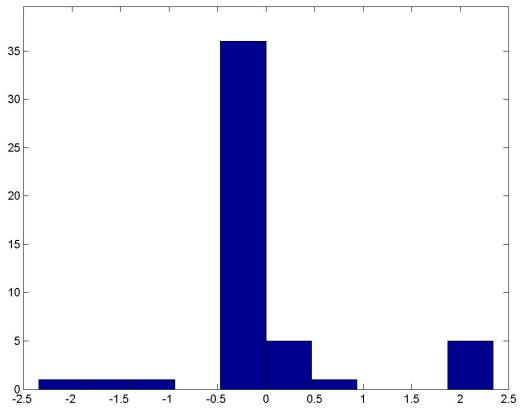

54

(C) International Monetary Fund. Not for Redistribution 
Figure A.12: Distribution of Macroeconomic Surprises: PPI and GDP

PPI

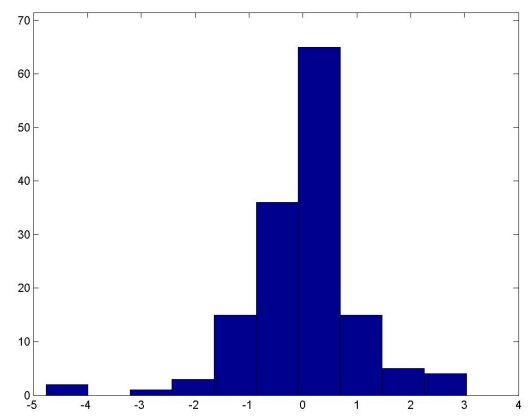

GDP

Full

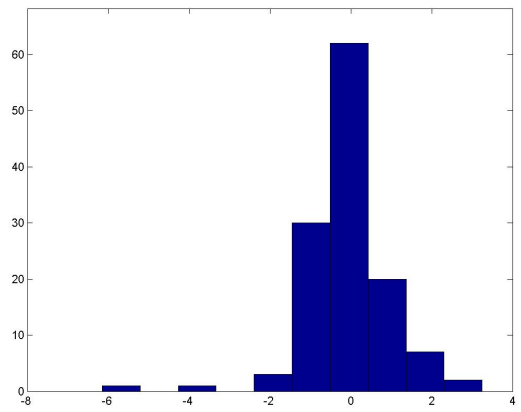

Pre-Disinflation
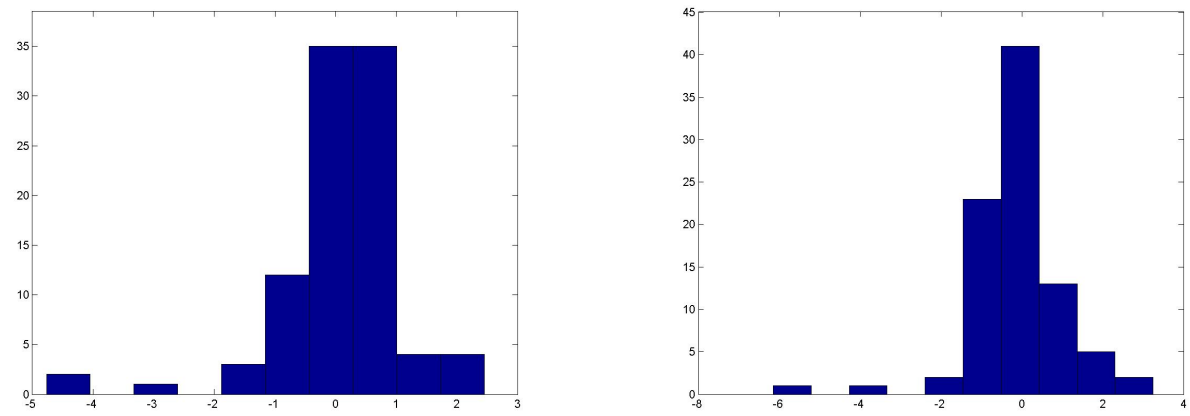

Pre-Disinflation

(Excluding 9 months period after Lehman Brothers collapse)
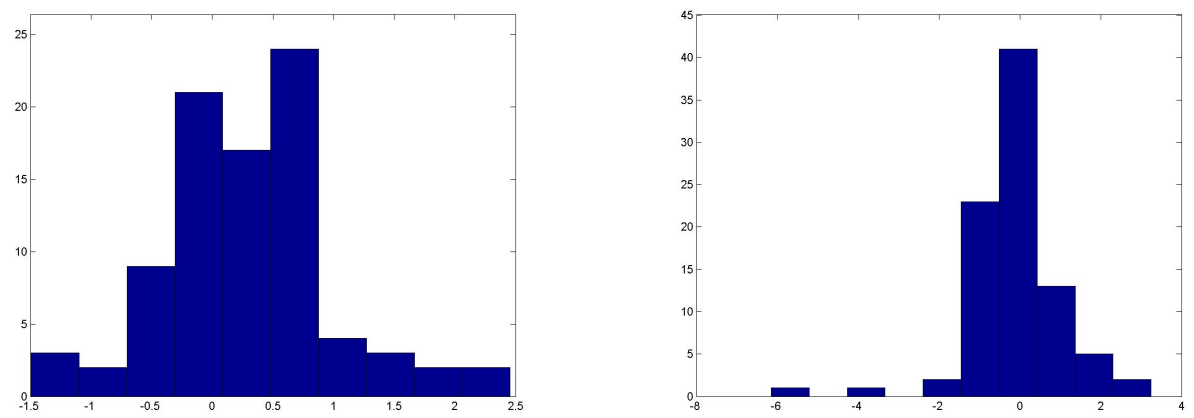

Below Target
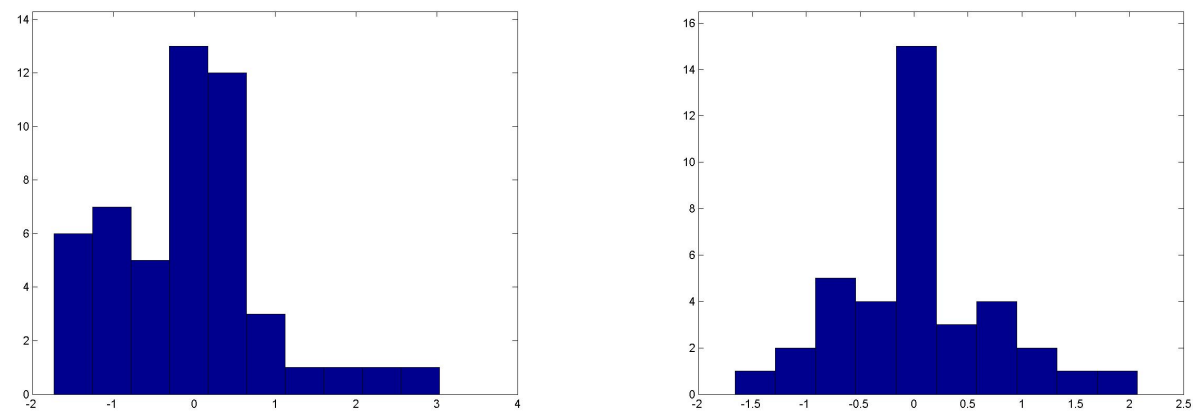
Figure A.13: Distribution of Macroeconomic Surprises: PMI and Consumer confidence

PMI

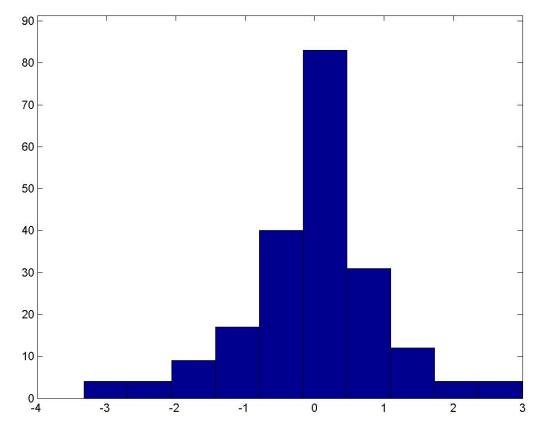

Consumer confidence

Full

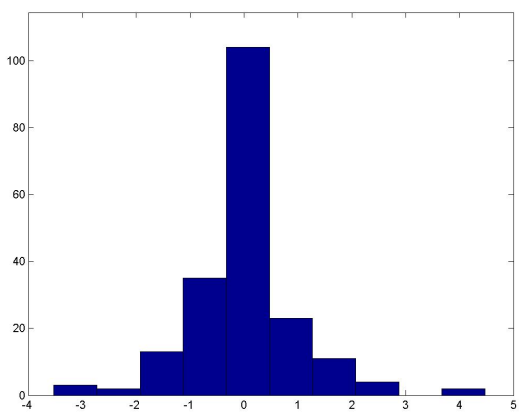

Pre-Disinflation
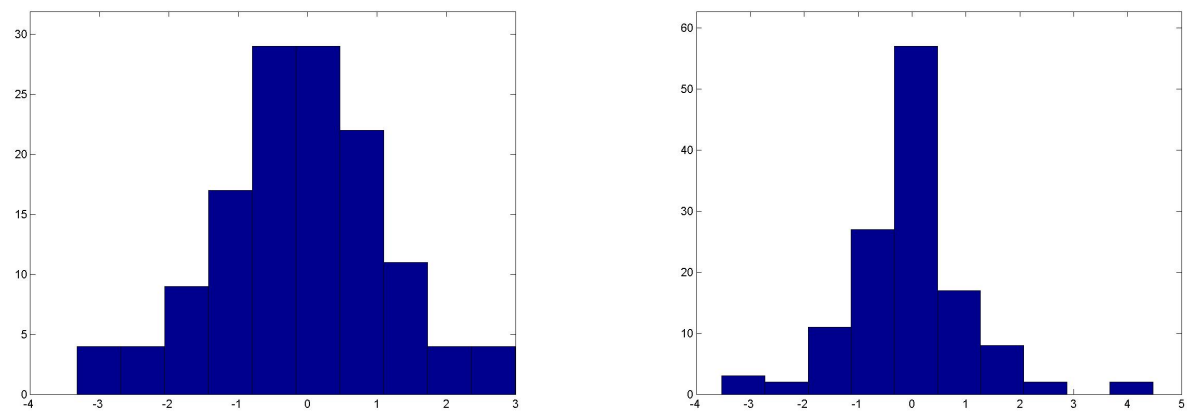

Pre-Disinflation

(Excluding 9 months period after Lehman Brothers collapse)
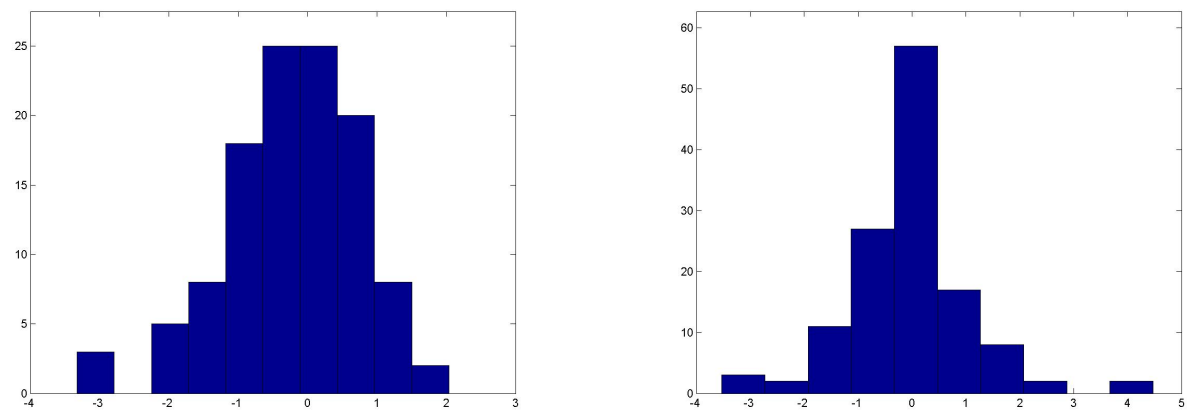

Below Target
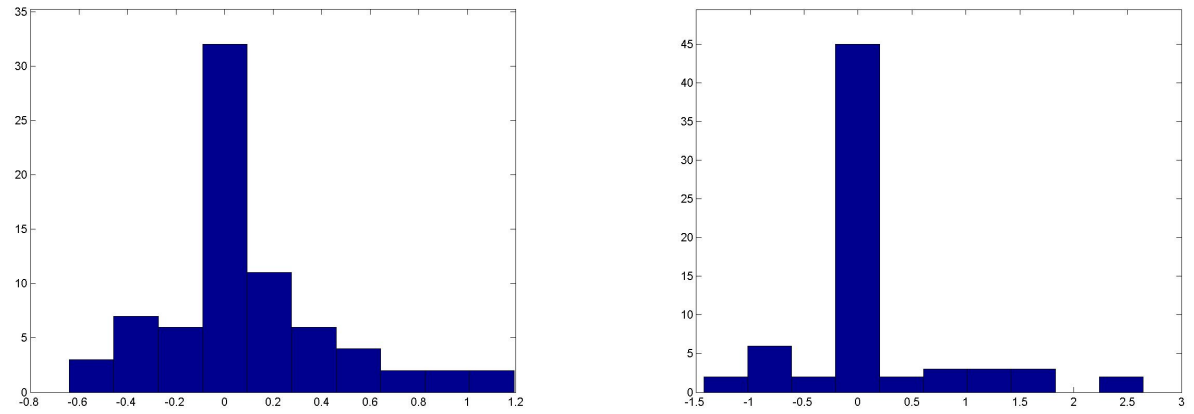
Figure A.14: Distribution of Macroeconomic Surprises: Industrial confidence and Industrial production

Industrial confidence

Full

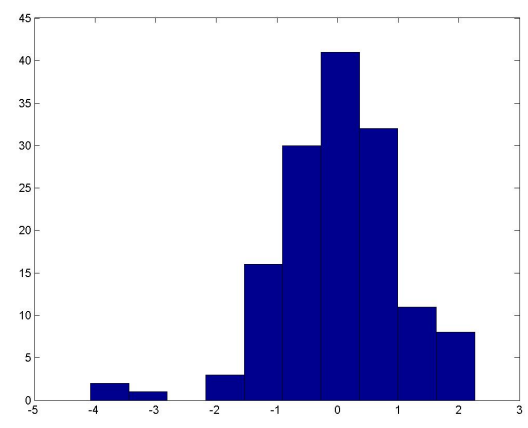

Industrial production

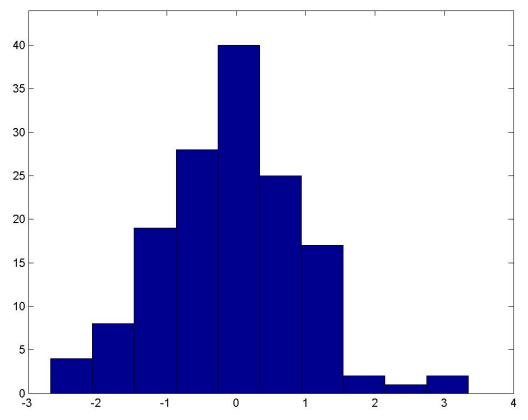

Pre-Disinflation
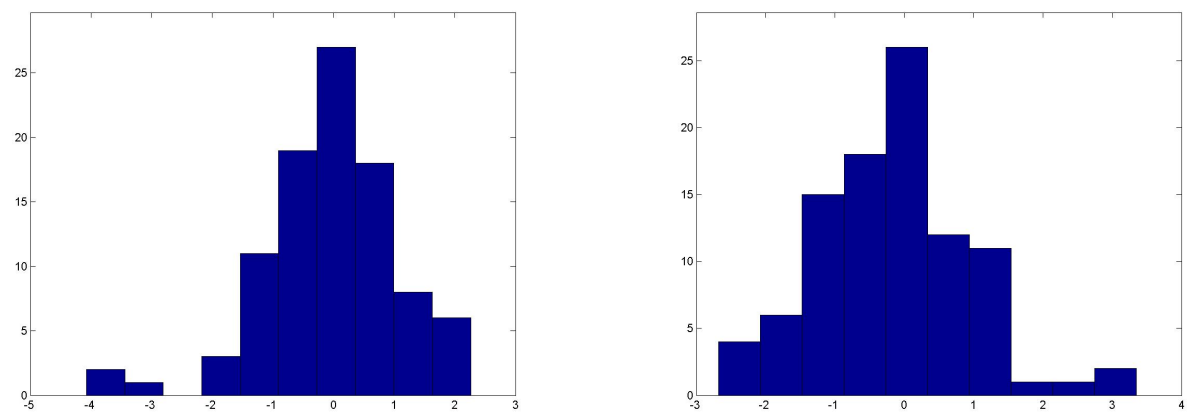

Pre-Disinflation

(Excluding 9 months period after Lehman Brothers collapse)
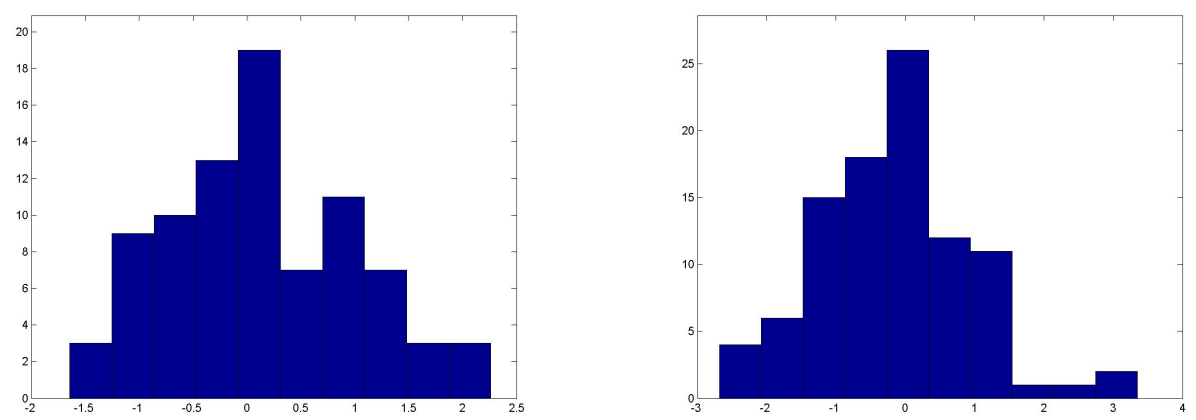

Below Target
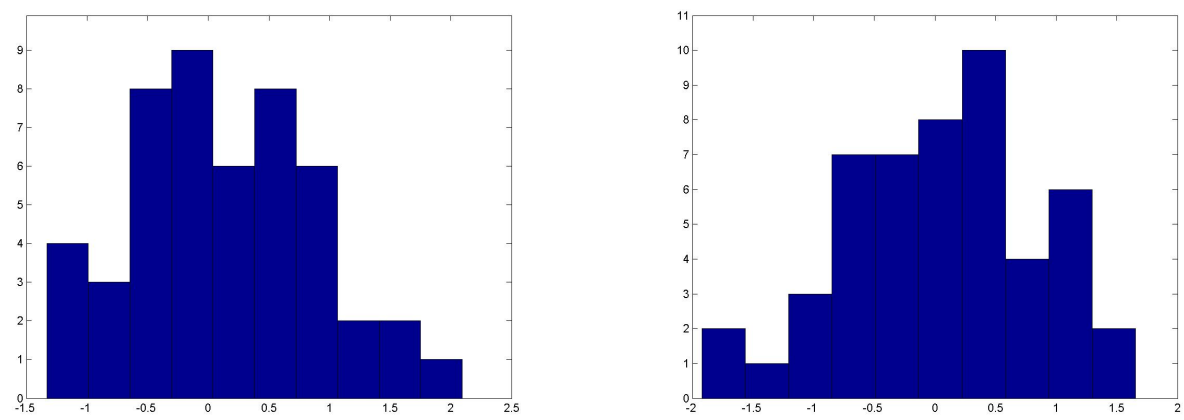

57

(C) International Monetary Fund. Not for Redistribution 
Figure A.15: Distribution of Macroeconomic Surprises: New orders and Unemployment rate

New orders

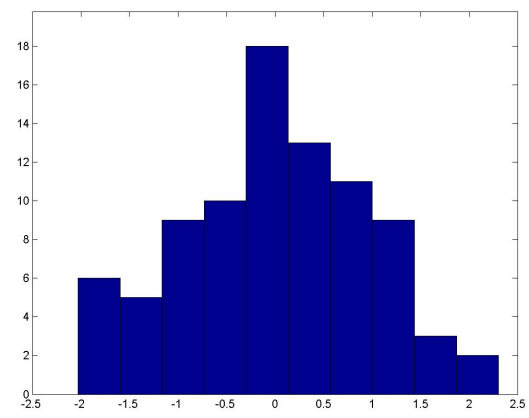

Unemployment rate

Full

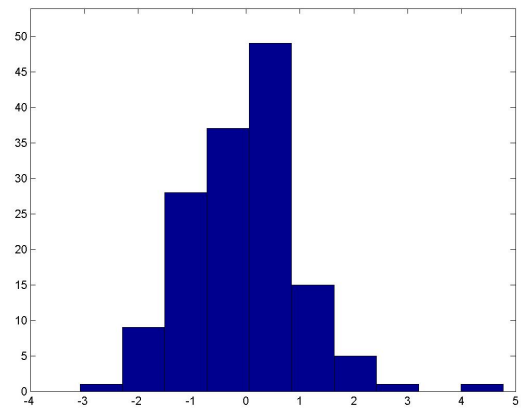

Pre-Disinflation
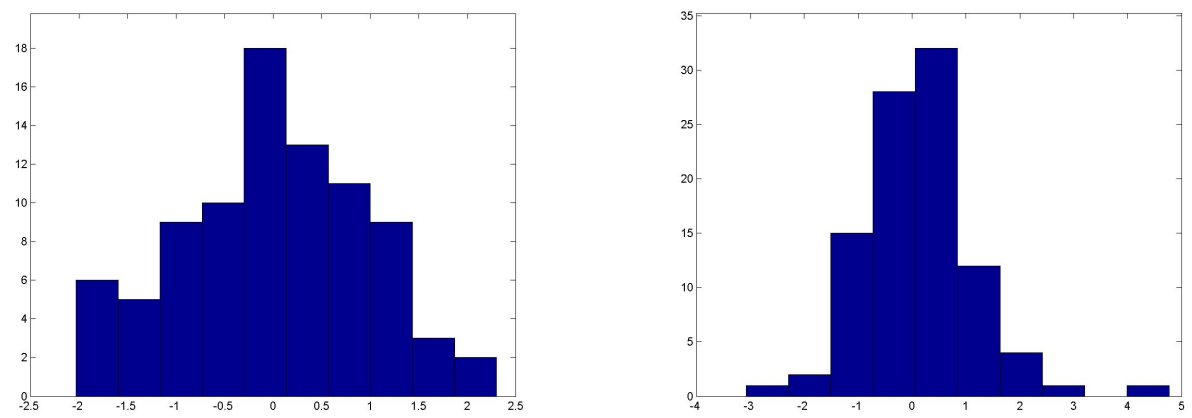

Pre-Disinflation

(Excluding 9 months period after Lehman Brothers collapse)
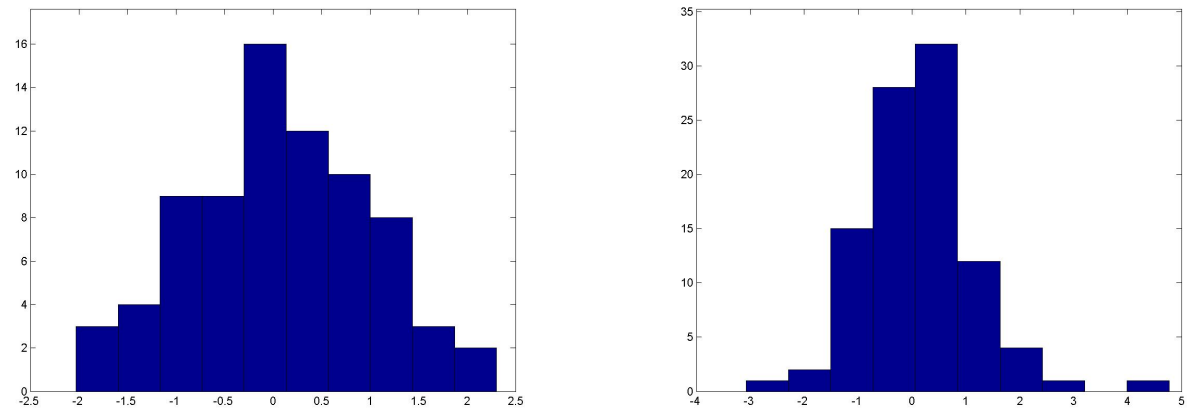

Below Target
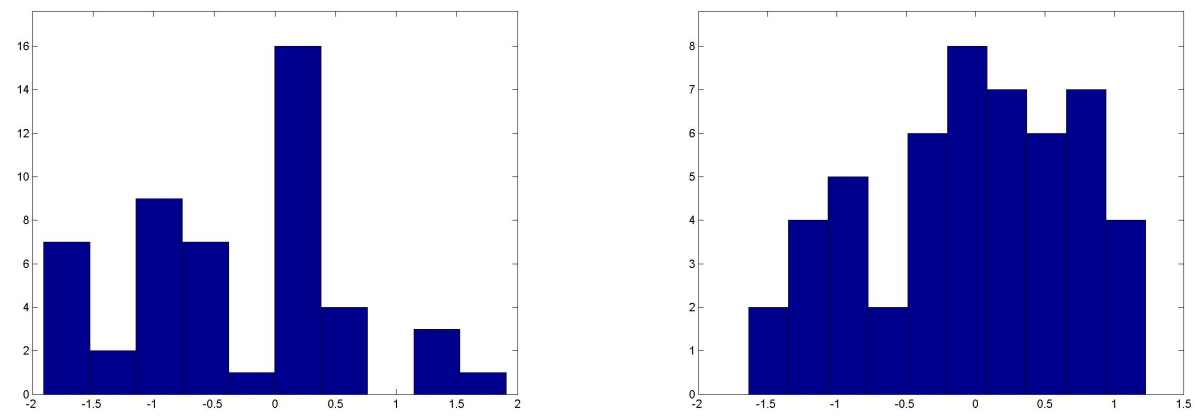
Figure A.16: Distribution of Macroeconomic Surprises: M3 and Retail sales

M3

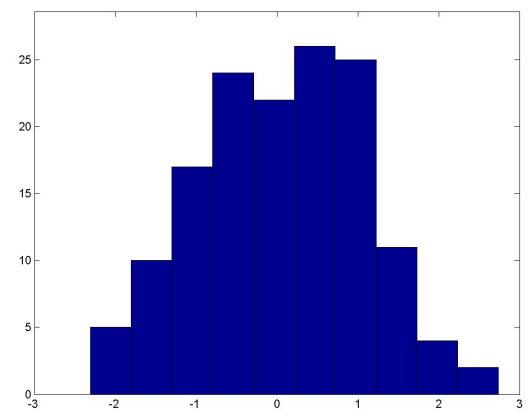

Retail sales

Full

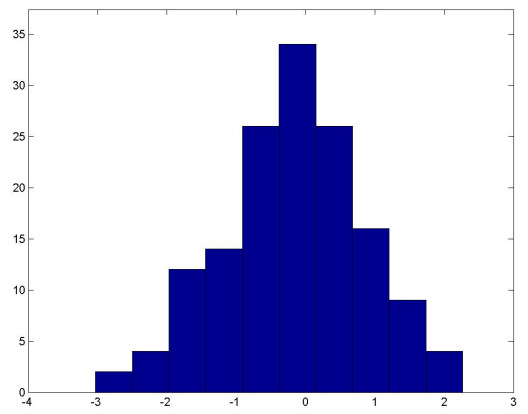

Pre-Disinflation
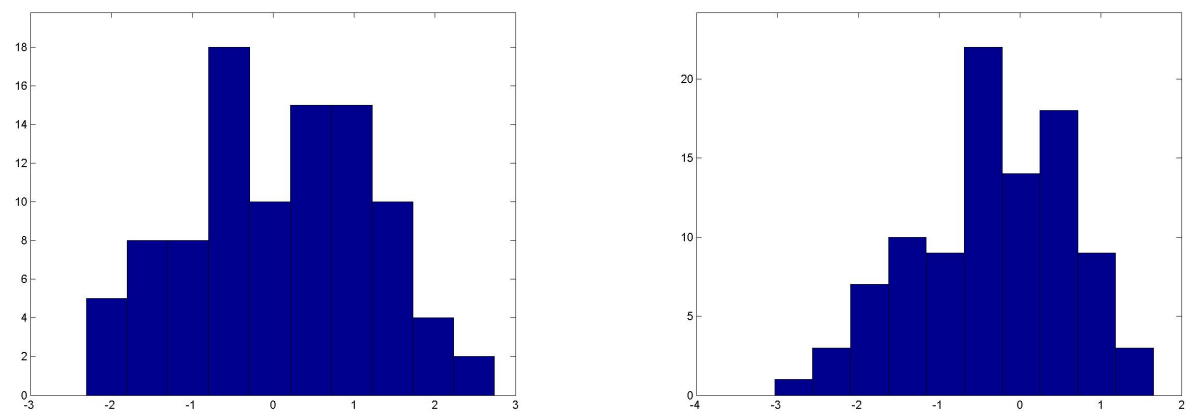

Pre-Disinflation

(Excluding 9 months period after Lehman Brothers collapse)
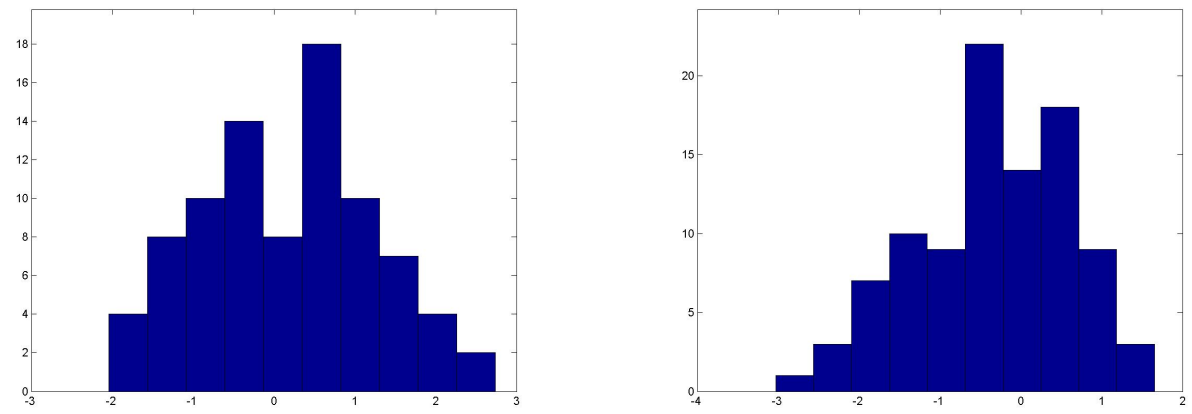

Below Target
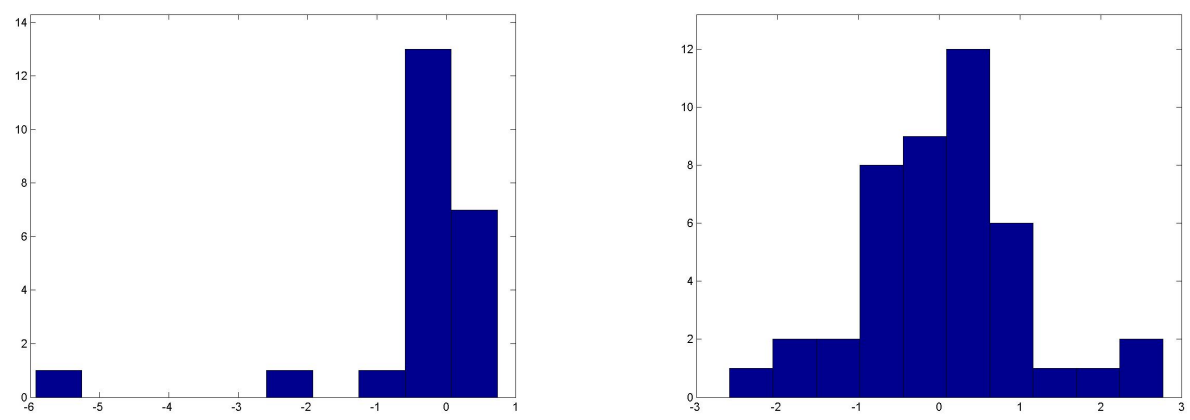